\title{
Encapsulation and Characterization of Meropenem in Niosome Nanoparticles and Inhibitory Effects of Antibiofilm and Antibacterial on Methicillin and Vancomycin Resistant Strains of Staphylococcus Aureus
}

Neda Jegargoshe Shirin

Islamic Azad University Damghan Branch

Tohid Piri Gharaghie ( $\square$ tohidpirie@yahoo.com )

Islamic Azad University Shahrekord Branch https://orcid.org/0000-0002-0041-5842

Sheida Beiranvand

Islamic Azad University Shahrekord Branch

Anali Riahi

Islamic Azad University Shahrekord Branch

Nasim Fattahi

Islamic Azad University East Tehran Branch

\section{Research}

Keywords: Staphylococcus aureus, MRSA, Niosomal meropenem, Encapsulation, Biofilm

Posted Date: February 16th, 2021

DOl: https://doi.org/10.21203/rs.3.rs-191656/v1

License: (a) (1) This work is licensed under a Creative Commons Attribution 4.0 International License.

Read Full License 


\title{
Encapsulation and characterization of Meropenem in Niosome nanoparticles and inhibitory effects of antibiofilm and antibacterial on methicillin and vancomycin resistant strains of
}

\section{Staphylococcus aureus}

\author{
Neda Jegargoshe Shirin ${ }^{1}$, Tohid Piri Gharaghie, ${ }^{2, *}$, Sheida Beiranvand ${ }^{3}$, Anali Riahi ${ }^{3}$, Nasim Fattahi $^{5}$ \\ ${ }^{1}$ Department of Biotechnology, Faculty of Basic Sciences, Damghan Branch, Islamic Azad University, Semnan, Iran \\ ${ }^{2}$ Biotechnology Research Center, Shahrekord Branch, Islamic Azad University, Shahrekord, Iran \\ ${ }^{3}$ Department of Biotechnology, Faculty of Basic Sciences, Shahrekord Branch, Islamic Azad University, Shahrekord, Iran \\ ${ }^{5}$ Department of Biotechnology, Faculty of Basic Sciences, East Tehran Branch, Islamic Azad University, Tehran, Iran
}

\begin{abstract}
A R T I C L E

Background: We aim to assess the antibacterial and anti-biofilm properties of niosome-encapsulated H I S T O R Y meropenem.

Received:

Methods: After isolating S. aureus isolates and determining their microbial sensitivity, their ability

Revised: to form biofilms was examined using plate microtiter assay. Various formulations of niosomeencapsulated meropenem were prepared using the thin-film hydration method, Minimum Biofilm

Accepted: Inhibitory Concentration (MBIC) and Minimum Inhibitory Concentration (MIC) were determined, and biofilm genes expression was examined. Drug formulations' toxicity effect on HDF cells were determined using MTT assay.

DOI:

Results: Out of the 162 separated Staphylococcus aureus, 106 were resistant to methicillin. 87 MRSA isolates were vancomycin-resistant, all of which could form biofilms. The F1 formulation of neoplastic meropenem with a size of $51.3 \pm 5.84$ and an encapsulation index of $84.86 \pm 3.14$ was detected, which prevented biofilm growth with a BDI index of $69 \%$ and reduced icaD, FnbA, Ebps biofilms' expression with $\mathrm{p} \leq 0.05$ in addition to reducing $\mathrm{MBIC}$ and $\mathrm{MIC}$ by 4-6 times. Interestingly, F1 formulation of neoplastic meropenem indicated cell viability over $90 \%$ at all tested concentrations.

Conclusions: Results of the present study indicate that niosome-encapsulated meropenem reduces the resistance of Staphylococcus aureus MRSA to antibiotics in addition to increasing its anti-biofilm and antibiotic activity, and could prove useful as a new strategy for drug delivery.
\end{abstract}

Keywords: Staphylococcus aureus, MRSA, Niosomal meropenem, Encapsulation, Biofilm

\footnotetext{
*Address correspondence to this author at the Biotechnology Research Center, Shahrekord Branch, Islamic Azad University, Shahrekord, Iran,

P.O. Box: 166, Shahrekord, Iran; Tel/Fax: +98-383-336-1001, +98-383-336-1001; E-mails: tohidpirie@yahoo.com
} 


\section{Introduction}

Staphylococcus aureus MRSA is among the most important hospital pathogens and an important factor contributing to hospital-acquired infections. This bacteria results in dangerous and purulent infections in patients and causes death in hospitalized patients (1). Staphylococcus aureus could cause a variety of infections such as septicemia, bacteremia, pneumonia, and infections in the skin, bones, and soft tissue (2). This bacteria is known to be the leading prevalent pathogen of hospital-acquired infections and is resistant to a wide variety of antibiotics such as methicillin (2). Since the mortality rate due to MRSA strains is quite high, the use of effective antibiotics started in the 1960s (3). The most important antibiotics selected for the experimental treatment of infections from Staphylococcus aureus's (MRSA) methicillin-resistant strains are meropenem and vancomycin (4). Meropenem (with the brand name of Merrem) is a broad-spectrum antibiotic used to treat various types of bacterial infections including pneumonia, meningitis, sepsis, and anthrax (5). Meropenem is usually prescribed as a strategic drug to treat patients suffering from systemic infections (6). According to previous research, using meropenem together with other antibiotics increases their strength against MRSA strains (7). However, meropenem overuse over the last decade has resulted in an increased population of enterococci with the meropenem resistance gene. Hence, there is a high probability of plasmids containing resistance gene transferring to Staphylococcus aureus strains through conjugation (8). Staphylococcus aureus strains resistant to methicillin have been identified since 1996 and are known to be a major challenge for healthcare systems (9). Besides, another reason for Staphylococcus aureus strains' resistance to antibiotics is biofilm formation which has become a great challenge in the field of hospital-acquired infections. Biofilms are cohesive microbial communities enclosed in an extracellular polymer matrix and form on animate or inanimate surfaces (10). Biofilms could result in many complications if formed on oil reservoirs, air-conditioning systems, and medical equipment such as prostheses and catheters. Besides, biofilms increase bacteria's resistance to antibiotics (11). Several genes are involved in bacterial biofilm formation (12). The first stage of biofilm formation is adhesion to surfaces which is facilitated by the bacterium's icaD gene binding. icaD ( $\mathrm{N}$-acetyl glucosamine transferase) makes up a major part of the exopolysaccharide matrix of the biofilm (13). Biofilm strength and maturity are then facilitated due to the expression of FnbA, Ebps elastin, and Bap fibronectin-binding genes (14). FnbA contains multiple fibronectin (Fn) substituents and binding regions, each one capable of joining both immobilized and soluble forms of Fn. This enables S. aureus to attack endothelial cells in vivo and in vitro with no need for additional factors (15). The elastin-binding protein (EbpS) is a $25 \mathrm{kDa}$ cell surface protein coded by the Ebps gene. The binding of S. aureus to the $30 \mathrm{kDa}$-terminal region of 
elastin that is the main component of elastic fibers' extracellular matrix leads S. aureus to colonize in the tissue (16). Bap is a protein associated with a cell wall that involves in the formation of biofilm (17). The spread of microbial resistance and the slow pace of producing new antibiotics over recent years have made researchers use nanotechnology to develop more and newer antibiotics. Low-cost production and causing no environmental issues are among the advantages that have turned nanoparticles into one of the suitable candidates for bacterial strain inhibition (18). Antimicrobial agent encapsulation in nanocarrier systems is among the most promising and effective ways that improve antibacterial activity as well as reducing side effects $(19,20)$. Niosomes have recently found a wide use to improve selective drug delivery and antimicrobial drugs' therapeutic efficacy. Niosomes are bilayer structures whose nonionic surfactants make them water-soluble and enables them to carry high drug doses (21). Niosomes have distinct features that could be used for the encapsulation of various drugs (22). The use of niosomes as antibacterial nanocarriers has recently attracted great attention from researchers (23). Hence, the present study has selected Meropenem as a strong antibiotic against Staphylococcus aureus MRSA strains to reduce antibiotic resistance and increase antimicrobial effects. In fact, the purpose of conducting this study was to develop niosome-encapsulated meropenem with improved antimicrobial activity against Staphylococcus aureus MRSA strains.

2. Methods and materials

2.1. Bacterial isolation and detection

2.1.1. Staphylococcus aureus isolates sampling, culture, and diagnosis

This descriptive study collected a total of 300 clinical samples from Shariati (100 samples), Firoozgar (100 samples), and Rasoul Akram (100 samples) hospitals in Tehran. Samples were cultivated in blood agar cultures using sterile swabs at $37^{\circ} \mathrm{C}$ for 24 hours. Staphylococcus aureus isolates were detected definitely using gram staining, catalase, mannitol fermentation, and DNase tests.

\subsubsection{Evaluation of isolated isolates' antibiotic sensitivity}

Strains' sensitivity to various antibiotics was examined by disk diffusion according to the Clinical and Laboratory Standards Institute (CLSI) method after Staphylococcus aureus strains were detected and confirmed. Staphylococcus aureus isolates' sensitivity to vancomycin (VA, $10 \mu \mathrm{g}$ ), cefoxitin (FOX, $10 \mu \mathrm{g}$ ), ciprofloxacin (CIP, $5 \mu \mathrm{g}$ ), clindamycin (CD, $2 \mu \mathrm{g}$ ), mupirocin (MU, $5 \mu \mathrm{g}$ ) and meropenem (MEM, $10 \mu \mathrm{g}$ ) (MAST, UK) disks were measured in Muller Hinton agar culture (Merck, Germany). It must be noted that cefoxitin antibiotic discs were used to detect MRSA methicillin 
resistance and Staphylococcus aureus ATCC 33592 standard strain was used as the positive control while Staphylococcus epidermidis 14990 ATCC was used as the negative control.

\subsubsection{Examining methicillin sensitivity through vancomycin agar screen}

Screening for resistance to vancomycin was performed according to the method proposed by Tiwary et al. $(2006,24)$ in a Brain Heart Infusion (BHI) culture containing 6 milligrams of vancomycin (BHI6V) per liter.

\subsubsection{Biofilm detection test}

Plate microtiter assay was used to determine isolates' ability to form biofilms. Through this assay, isolates were incubated at $37^{\circ} \mathrm{C}$ for 24 hours after cultivation in a TBS culture containing $0.5 \%$ glucose. After emptying wells' contents and washing with phosphate-buffered saline solution (PBS), staining was performed using $1 \%$ violet crystal. Afterward, $10 \%$ sample and Ethanol (70\% concentration) were added to each well and their light absorbance was examined using ELISA Reader Stat Fax2100 (Awareness Technology, Ukraine) at a 570nm wavelength. Biofilm formation results were reported in four classifications including non-binding (OD $\leq 0.083)$, weak (ODC $<\mathrm{OD} \leq 2 \times$ $\mathrm{ODC})$, moderate $(2 \times \mathrm{ODC}<\mathrm{OD} \leq 4 \times \mathrm{ODC})$, and strong $(\mathrm{OD}>4 \times \mathrm{ODC} 2)$.

2.1.5. Molecular detection of icaD, FnbA, Ebps, and Bap biofilm genes and the gene resistance to vancomycin VanB

Genomic DNA of the bacterium was obtained using the instructions of the Sina Gene company extraction kit (Cinna Pure DNA KIT, Alborz, Iran), and the purity obtained at the wavelength of $260 \mathrm{~nm}$ was confirmed by a spectrophotometer. The M-PCR test was conducted to detect biofilm decoding genes, icaD, FnbA, Ebps, Bap, and the gene resistant to vancomycin VanB through polymerase chain reaction using oligonucleotide sequences of specific primers indicated in Table 1. Final reaction volume $(20 \mu \mathrm{L})$ was considered to contain $12 \mu \mathrm{L}$ PCR master mix (PCR buffer, $\mathrm{MgCl} 2$, dNTP, 0.2 units of Taq polymerase), $0.5 \mu \mathrm{L}$ reverse primer, $0.5 \mu \mathrm{L}$ forward primer, $1 \mu \mathrm{L}$ template cDNA, and $6 \mu \mathrm{L}$ distilled water (Amplicon, Denmark). The PCR program was performed in the form of an initial denaturation at $95^{\circ} \mathrm{C}$ for five minutes and 35 initial denaturation cycles for one minute at $94^{\circ} \mathrm{C}$, one minute of connection at $58^{\circ} \mathrm{C}$, one minute of extension at $72^{\circ} \mathrm{C}$, and a final extension at $72^{\circ} \mathrm{C}$ for five minutes. The amplified products were investigated through $1 \%$ agarose gel electrophoresis to detect the desired genes. 


\subsection{Preparation of niosomes encapsulated Meropenem}

\subsubsection{Formulation and encapsulation of meropenem in noisome}

According to instructions provided by previous studies $(25,26)$. noisome-encapsulation of meropenem was conducted through thin-film hydration and 4 drug compounds were prepared as follows. The first compounds were prepared. The first compound contained Span 60 (CAS: 1338-41-6) (Henan Daken Chemical CO., LTD., China) and Tween 60 (CAS: 9005-67-8) (career Henan chemical co, China) mixed with cholesterol (CAS: 57-88-5) (Capot Chemical Co., Ltd., China) with respective molar ratios of 3:3:4 and was dissolved in 10ml of chloroform and methanol mixed with respective ratios of 2:1. The second compound contained Span 40 (CAS: 26266-57-9) (Henan Daken Chemical CO., LTD., China) and Tween 40 (CAS: 9005-66-7) (Shanghai Jizhi Biochemical Technology Co., Ltd, China) Mixed with cholesterol (CAS: 57-88-5) (Capot Chemical Co., Ltd., China) with respective molar ratios of 3:3:4 and was dissolved in $10 \mathrm{ml}$ of chloroform and methanol mixed with respective ratios of 2:1. The third compound contained Span 60 and Tween40 mixed with cholesterol with respective molar ratios of 3:3:4 and was dissolved in $3 \mathrm{ml}$ of chloroform and methanol mixed with respective ratios of 2:1(Table1). After adding glass beads to all four compounds, drug compound solvents were evaporated using a rotary evaporator (Heidolph, Germany) for one hour at $60^{\circ} \mathrm{C}$ and $120 \mathrm{rpm}$ rotation. Afterward, dried thin films were hydrated for one hour using a solution of meropenem dissolved in $10 \mathrm{ml}$ of PBS at $60^{\circ} \mathrm{C}$ with a speed of $120 \mathrm{rpm}$ to obtain different niosome formulations. The resulting particles were sonicated using a probe sonicator in an ice bath using SONOPULS ultrasonic homogenizers (amplitude: 25\%, $200 \mathrm{wt}$ ) for five minutes to reduce the size of niosomes containing meropenem, and samples were stored at $4{ }^{\circ} \mathrm{C}$ for next experiments.

Table 1: the sequence of various formulations and primers of niosome-encapsulated meropenem

\begin{tabular}{|c|c|c|c|c|c|c|c|}
\hline \multicolumn{3}{|c|}{ Primers used for screening } & \multicolumn{5}{|c|}{ Different Formulations of Niosomal Meropenem } \\
\hline \multicolumn{2}{|l|}{ Genes } & Primer Sequence $5^{\prime} \rightarrow 3^{\prime}$ & Formulations & $\begin{array}{l}\text { Different } \\
\text { compounds of } \\
\text { surfactant: } \\
\text { Cholesterol }\end{array}$ & $\begin{array}{l}\text { Span+ Tween+ Cholesterol } \\
\text { molar ratio }\end{array}$ & $\begin{array}{l}\text { Span: Tween } \\
\text { molar ratio }\end{array}$ & $\begin{array}{l}\text { Drug } \\
\text { concentrat } \\
\text { ion } \\
(\mathrm{mg} / \mathrm{ml})\end{array}$ \\
\hline \multirow{3}{*}{$\begin{array}{l}\text { Reference } \\
\text { gene }\end{array}$} & \multirow[t]{3}{*}{ 16SrRNA } & \multirow{3}{*}{$\begin{array}{l}\text { F: ATCGTTTTATCGGGACCATC } \\
\text { R:TCATTAACTACAACGTAATCGTA }\end{array}$} & \multirow{3}{*}{$\mathrm{F} 1$} & \multirow{3}{*}{$\begin{array}{l}\text { Span 60+ Tween } \\
60+\text { Cholesterol }\end{array}$} & \multirow{3}{*}{$3: 3: 4$} & $50: 50$ & 1 \\
\hline & & & & & & $25: 75$ & 1 \\
\hline & & & & & & $75: 25$ & 1 \\
\hline \multirow{8}{*}{$\begin{array}{l}\text { Biofilm } \\
\text { genes }\end{array}$} & \multirow[t]{3}{*}{ icaD } & \multirow{3}{*}{$\begin{array}{l}\text { F:ACCCAACGCTAAAATCATCG } \\
\text { R:GCGAAAATGCCCATAGTTTC }\end{array}$} & \multirow{3}{*}{$\mathrm{F} 2$} & \multirow{3}{*}{$\begin{array}{l}\text { Span } 40+\text { Tween } \\
40+\text { Cholesterol }\end{array}$} & \multirow{3}{*}{$3: 3: 4$} & 50:50 & 1 \\
\hline & & & & & & $25: 75$ & 1 \\
\hline & & & & & & $75: 25$ & 1 \\
\hline & \multirow[t]{3}{*}{ FnbA } & \multirow{3}{*}{$\begin{array}{l}\text { F:AAATTGGGAGCAGCATCAGT } \\
\text { R:GCAGCTGAATTCCCATTTTC }\end{array}$} & \multirow{3}{*}{ F3 } & \multirow{3}{*}{$\begin{array}{l}\text { Span 60+ Tween } \\
40+\text { Cholesterol }\end{array}$} & \multirow{3}{*}{$3: 3: 4$} & $50: 50$ & 1 \\
\hline & & & & & & $25: 75$ & 1 \\
\hline & & & & & & $75: 25$ & 1 \\
\hline & Ebps & $\begin{array}{l}\text { F:GGTGCAGCTGGTGCAATGGGTGT } \\
\text { R:GCTGCGCCTCCAGCCAAACCT }\end{array}$ & \multirow{3}{*}{$\mathrm{F} 4$} & \multirow{3}{*}{$\begin{array}{l}\text { Span } 40+\text { Tween } \\
60+\text { Cholesterol }\end{array}$} & \multirow{3}{*}{$3: 3: 4$} & $50: 50$ & 1 \\
\hline & Bap & $\begin{array}{l}\text { F: ATCGTTTTATCGGGACCATC } \\
\text { R:TCATTAACTACAACGTAATCGTA }\end{array}$ & & & & $25: 75$ & 1 \\
\hline $\begin{array}{l}\text { Vancomycin } \\
\text { resistance gene }\end{array}$ & VanB & $\begin{array}{l}\text { F: GTG ACA AAC CGG AGG CGA GGA } \\
\text { R: CCG CCA TCC TCC TGC AAA AAA }\end{array}$ & & & & $75: 25$ & 1 \\
\hline
\end{tabular}




\subsubsection{Noisome-encapsulated meropenem morphological characteristics}

The averages size, size distribution, and zeta potential of meropenem loaded in noisome were obtained using dynamic light scattering (DLS) and ZetaPlas palladium electrodes (Brookhaven Instruments Corp., USA). Various newlyprepared niosome formulations were diluted two times using distilled water with a ratio of 20:1 to prevent multiple scattering as a result of interactions between particles, and analysis was conducted at $25^{\circ} \mathrm{C}$ with a 90 -degree light scattering angle. Average $\mathrm{z}$ diameter and niosome multiple scattering index were determined and their zeta potentials were measured. Niosome-encapsulated meropenem particles were coated with a gold layer to generate electrical conductivity and were examined using a field scanning electron microscope (FESEM) device model MIRA3 (TESCAN, Czech Republic) and an XRD device model X 'Pert Pro (Panalytical, Netherlands).

\subsubsection{Entrapment efficiency (EE)}

Encapsulation efficiency was obtained by determining the amount of non-capsulate meropenem (free meropenem) in the formed niosomes. Noisome-encapsulated meropenem particles were isolated over an hour at $4^{\circ} \mathrm{C}$ in a refrigerated centrifuge at 1400rpm. The meropenem content of the supernatant was examined through ELISA Reader Stat Fax2100's (Awareness Technology, Ukraine) light absorbance reading of the supernatant at 276nm wavelength and the EE percentage was obtained based on Formula 1.

Formula 1:

$\% \mathrm{EE}=[($ Drug added - Free "unentrapped drug")/Drug added $] \times 100$

\subsubsection{Evaluation of noisome-encapsulated release and stability}

Dialysis was employed to examine meropenem's release of the noisome. The dialysis tube was soaked in distilled water for 24 hours. $0.5 \mathrm{ml}(10 \mathrm{mg})$ of meropenem-loaded noisome was put in the dialysis bag and $0.5 \mathrm{ml}$ meropenem antibiotic aqueous solution containing 10mg meropenem was also used as a control sample. Dialysis bags were immersed in conical flasks in $75 \mathrm{ml}$ distilled water and were shaken at $50 \mathrm{rpm}$ in a water bath at $37^{\circ} \mathrm{C} .5 \mathrm{ml}$ was withdrawn from the receptor medium at intervals of one, two, four, six, 12, and 24 hours and meropenem were measured in terms of spectrophotometry at $281 \mathrm{~nm}$. Aliquots of samples were replaced with a new medium at $37^{\circ} \mathrm{C}$ and diffusion profile was determined using various kinetic models. This method was used to monitor the stability of 
various niosome-encapsulate meropenem formulations' diffusion at intervals of 7, 14, 21, 28, 35, 42, 49, and 56 days for a storage period of two months at $25^{\circ} \mathrm{C}$.

2.3. Examination of the antibacterial and anti-biofilm features of noisome-encapsulated meropenem

\subsubsection{Antibacterial activity of noisome-encapsulated meropenem}

Antibacterial activity of various noisome-encapsulated meropenem formulations against Staphylococcus aureus MRSA strains was examined through broth microdilution. The amounts of Minimum inhibitory concentration (MIC) and minimum bactericidal concentration (MBC) were then determined as follows. After culturing Staphylococcus aureus in Müller-Hinton broth for 24 hours, $5 \times 105 \mathrm{CFU} / \mathrm{mL}(5 \mu \mathrm{l})$ bacteria, $100 \mu \mathrm{l}$ of various niosome-encapsulated meropenem formulations, free meropenem and free niosome (in a concentration ranging from 0.03 to $64 \mu \mathrm{g} / \mathrm{ml}$ ), and $95 \mu \mathrm{l}$ pure Hinton broth were poured in each well of the 96 -well plate and were incubated for 24 hours at $37^{\circ} \mathrm{C}$. The sub-MIC values of (highest drug concentration that does not affect the growth of the bacteria), negative control well (containing pure culture medium), and positive control well (containing culture medium plus standard Staphylococcus aureus strain ATCC 33592) were determined, and the test was replicated for a second time.

\subsubsection{Anti-biofilm activity of niosome-encapsulated meropenem}

a. Inhibition of biofilm formation

Sub-MIC concentrations of free meropenem and niosome and various formulations of niosome-encapsulated meropenem were used to determine Minimum Biofilm Inhibition Concentration (MBIC) against the six S. aureus strains making up the biofilm $\mathrm{S}_{\mathrm{MRSA} 1}, \mathrm{~S}_{\mathrm{MRSA} 2}, \mathrm{~S}_{\mathrm{MRSA} 3}, \mathrm{~S}_{\mathrm{MRSA} 4}, \mathrm{~S}_{\mathrm{MRSA} 5}, \mathrm{~S}_{\mathrm{MRSA}}$ ) and standard S. aureus ATCC 33592. The wells of the 96 -well plate were filled with $100 \mu$ d drug sample and $00 \mu l$ of the bacteria cultured in Müller Hinton Broth. The plates were incubated for 48 hours at $37^{\circ} \mathrm{C}$ and were stained with violet crystal after being washed. The tests were replicated two times and the mean MBIC was determined to be OD630 $<0.1$.

b. Analysis of biofilm gene expression

The expressions of the biofilm genes of icaD, FnbA, Ebps, and Bap were examined through polymerase chain reaction (qRT-PCR) using the specific primers indicated in Table 1. RNA was extracted from resistant MRSA bacteria using RNX-Plus kit (Sina gene, Iran) after 24 hours of being exposed to sub-MIC concentrations of free meropenem and niosome-encapsulated meropenem, and cDNA was fabricated based on the RNA extracted from treated and untreated 
bacteria according to the protocol of the YTA Kit (Yekta Tajhiz, Iran). Biofilm gene expression to 16SrRNA gene (as the reference gene) was examined using a real-time PCR device model Corbett 5 Plex HRM (Corbett, Australia). The final reaction volume was $15 \mu \mathrm{l}$, containing $1 \mu \mathrm{l}$ of cDNA, $1 \mu \mathrm{l}$ of the forward primer and $1 \mu \mathrm{l}$ of reverse primer, $8 \mu \mathrm{l}$ of master mix and 4 of $\mu$ deionized water (Merck, Germany), and the temperature cycle included initial denaturation for five minutes at $95^{\circ} \mathrm{C}$ followed by 40 cycles of 20 seconds at $95^{\circ} \mathrm{C}, 40$ seconds at $58^{\circ} \mathrm{C}$, and 40 seconds at $72^{\circ} \mathrm{C}$. The final stage was selected to be at $53-95^{\circ} \mathrm{C}$ to draw melting curves. Genes' quantitative relative expression was examined using the $\Delta \Delta \mathrm{Ct}$ method.

\section{c. Inhibition of biofilm growth}

According to Vyas (2007) method (27), the effectiveness of niosome-encapsulate meropenem's biofilm growth inhibition through adhesion to model biofilms was determined by measuring the OD630 reduction of biofilms exposed to free and niosome-encapsulated meropenem for two hours. Biofilm-containing wells were treated with $200 \mu \mathrm{l}$ niosome-encapsulated meropenem with various concentrations $(0.5,0.75,1,1.5$, and two times the MIC for the respective strains). Free meropenem and meropenem mixed with blank niosome were used as control samples. After two hours of incubation at $37^{\circ} \mathrm{C}$, the liquid contents of each well were aspirated and biofilms were washed with ethanol. Afterward, antibiotic-free culture was added to wells and the liquid content of biofilm and aspirate were fixed and washed. Biofilms were then stained using violet crystal, their light absorbance was measured using LISA Reader Stat Fax2100 (Awareness Technology, Ukraine) at $630 \lambda \max n m$ wavelength, and the amount of biofilm growth inhibition (\%BGI) was determined using Formula 2.

Formula 2:

$$
B G I \%=\{"[\text { OD } 630 \times \text { Untreated Biofilm }]-[\text { OD630 } \times \text { Treated Biofilm }] " \div[\text { OD } 630 \times \text { Untreated Biofilm }]\} \times 100
$$

\subsection{Cytotoxicity study}

\subsubsection{MTT assay}

Dermal Fibroblasts are responsible for producing the extracellular matrix forming the connective tissue of the skin, and play a crucial role during wound healing. HDF provide an excellent model system to study many aspects of cell physiology, and have been utilized in dozens of research publications, particularly those related to skin biology and reprogramming/induced pluripotency studies (28). One of the methods of cytotoxicity test to measure the rate of cell 
death is the MTT method, which is based on the formation of Formosan dye by reduction of MTT (dimethyl thiazole 2 and 5 diphenyltetrazolium bromide) or other tetrazolium salts. By breaking the MTT tetrazolium ring by mitochondrial enzymes in living cells, crystals of Insoluble purple are formed. The formation of these crystals indicates the activity of respiratory chain enzymes and is a measure of cell viability (29). According to standard ISO10993-5 and Li et al. Method (2015) (30), the cytotoxicity test was performed by MTT method on HDF cells. To check the cytotoxicity, place an L929 Confluence flask under the hood and in fully sterile Condition DMEM High Glu (Catalog number 11965118) (Thermo Fisher Scientific, United States) Surface culture medium of the cell emptied. The surface of the cells was washed with PBS and trypsin was added to remove the cells from the fibroblastic state and make them spherical. Then DMEM containing 10\% FBS (bovine fetal serum) was poured on them to neutralize trypsin and the cells were poured into a falcon tube and were centrifuged at 1200rpm for 5 minutes. The supernatant was discarded and DMEM containing 10\% FBS was poured and cell count was performed by a Neobar slide. For each well, a 24-cell plate of 5×104 cells was considered. Sterile samples of free Meropenem and Niosomal encapsulated Meropenem were also placed in the center of each plate under sterile conditions and the cell suspension was added and placed in a $37^{\circ} \mathrm{C}$ incubator containing $\mathrm{Co} 2$ for 24 hours. According to standard ISO10993-5, after 24 hours, the cell surface was removed and the cell layer was washed with PBS, and then a sufficient amount of MTT (1mg/ml) was poured onto the cell layer. The culture plate was incubated for 3 to 5 hours and the cells were then washed with PBS to remove unreacted MTT. The product of Formosan solvent by isopropanol and OD560 nm of each cell was evaluated. Cell viability was obtained from the absorption fraction of each sample on the control sample (polystyrene container). Also, the percentage of living cells or the rate of cell survival was calculated based on the following equation:

Formula 3:

Viable cell percentage $\%=$ treated cells mean absorbance/control cells mean absorbance $\times 100$

3. Results

3.1. Staphylococcus aureus frequency

Out of the 300 collected samples, 162 cases were confirmed to contain Staphylococcus aureus after microbial diagnostic tests, and further molecular examination by 16SrRNA gene confirmed the identification of Staphylococcus aureus strains. As Table 2 indicates, Shariati Hospital with the highest frequency of 67 patients (41.3\%), Rasoul Akram 
Hospital with 59 patients (36.41\%), and Firuzgar Hospital with the lowest frequency of 36 patients (22.22\%) ranked first to last in terms of Staphylococcus aureus infection considering the number of samples taken from the hospitals under study. Afterward, the sensitivity of Staphylococcus aureus isolates to various antibiotics was studied which indicated that out of the 162 studied samples, 134 isolates (82.71\%) were multiple-drug resistant (MDR) while 106 isolates (65.43\%) were methicillin-resistant (MRSA). Vancomycin screen agar results indicated that 87 isolates (82.07\%) of MRSA strains were vancomycin-resistant. Also, the highest frequency of methicillin-resistant Staphylococcus aureus (MRSA) was observed in Shariati Hospital with 42.45\% (45 isolates) while samples from Firouzgar hospital indicated 32.07\% (34 isolates) resistance and the lowest frequency of methicillin-resistant Staphylococcus aureus (MRSA) was observed in Rasoul Akram Hospital with a percentage of 25.47 (27 isolates). Besides, 97 samples (72.38\%) out of the 134 MDR isolates were capable of forming biofilms, and the highest frequency of observed in Shariati, Rasoul Akram, and Firouzgar Hospitals with respective isolate numbers of 47 (48.48\%), $33(34.02 \%)$ and $17(17.52 \%)$.

Table 2: screening and determining the frequency of Staphylococcus aureus MRSA and MDR in biofilms from various hospitals

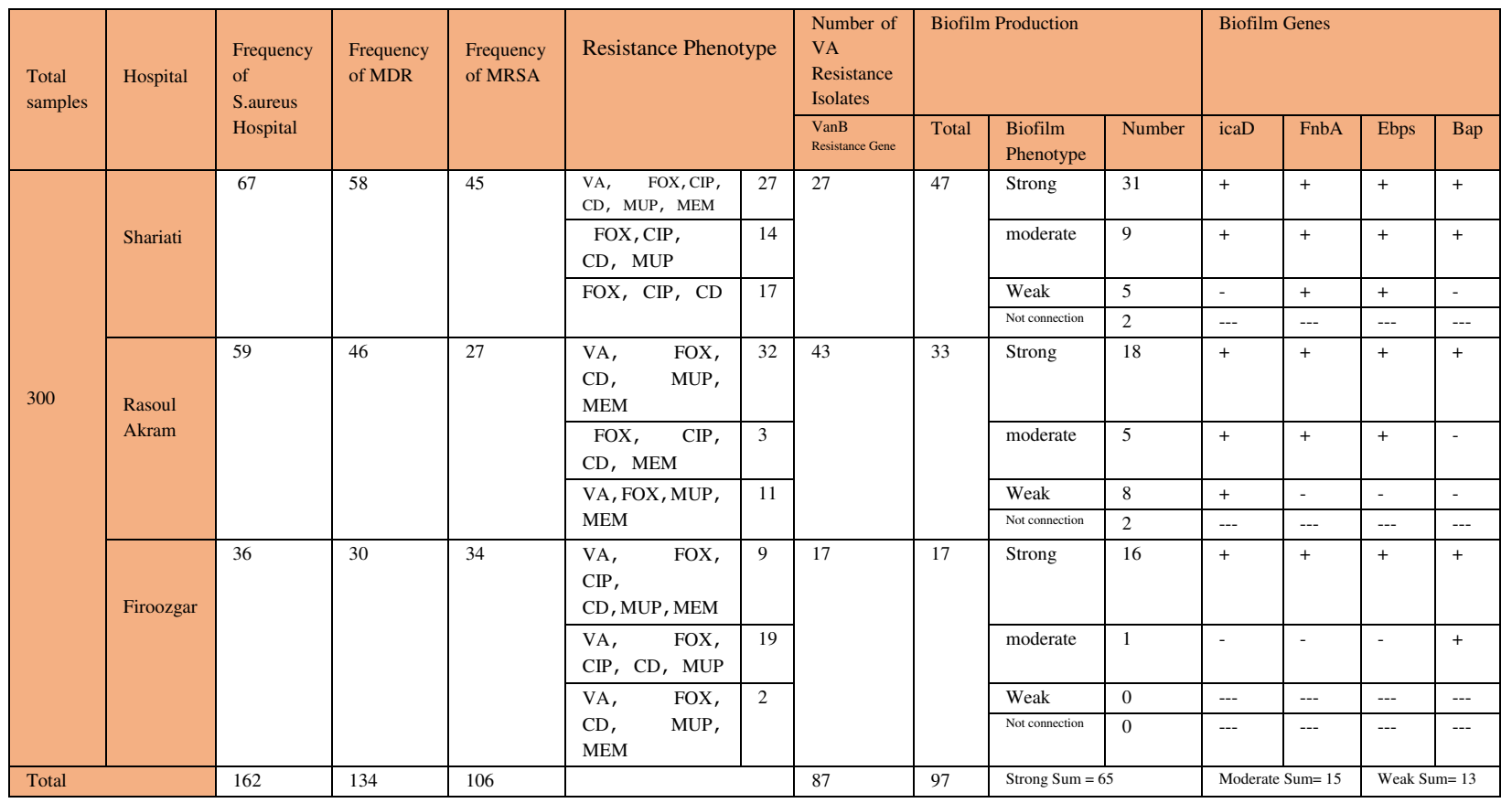

Afterward, various formulations of niosome-encapsulated meropenem were studied morphologically and in terms of various indicators such as surfactant to cholesterol ratio, Span to Tween ratio, and the composition of different surfactants' Span and Tween (Table 1). Each of the formulations had a distinct size, polydispersity index (PDI), and 
entrapment efficiency (EE). Dynamic Light Scattering (DLS) revealed that various formulations of niosomeencapsulated meropenem had good uniformity (Table 3). As demonstrated, F1 is of a smaller and better size and is associated with surfactant Span60's hydrophile-lipophile balance. Span60 has a hydrophile-lipophile balance of 4.7 while the corresponding value in Span40 is 6.7. Therefore, nanoparticles formulated with Span60 are smaller. Besides, the EE content of the F1 formulation is higher than other formulations which might be due to the surfactant used. A longer saturated alkyl chain is directly associated with the permeability of drugs in niosomes so that longer saturated alkyl chains will result in greater permeability. Span60 has a longer alkyl chain compared to Span40, which is why formulations incorporating Span60 have higher indexes and EE content is at its peak in F1 formulation. The polydispersity indexes (PDI) smaller than 0.3 indicate a suitable distribution of small nanoparticles, indicating the F1 formulation to be the optimal one given that it has the smallest PDI.

Table 3: morphological features of niosome-encapsulated meropenem compared to blank niosomes

\begin{tabular}{|l|l|l|l|l|}
\hline Formulations & $\begin{array}{l}\text { Polydispersity index } \\
(\text { average } \pm \text { SD) }\end{array}$ & Zeta Potential (m.v) & Vesicle size (nm) (SEM) & EE $(\%)$ \\
\hline Blank niosome & $0.314 \pm 0.99$ & $-75.12 \pm 1.75$ & $0.615 .42 \pm 0.84$ & --- \\
\hline F1 & $0.131 \pm 0.014$ & $-65.29 \pm 2.68$ & $51.3 \pm 5.84$ & $84.86 \pm 3.14$ \\
\hline F2 & $0.272 \pm 0.025$ & $-68.75 \pm 2.84$ & $218.1 \pm 14.26$ & $63.28 \pm 1.83$ \\
\hline F3 & $0.163 \pm 0.004$ & $-67.85 \pm 2.12$ & $96.8 \pm 7.21$ & $76.08 \pm 0.23$ \\
\hline F4 & $0.192 \pm 0.016$ & $-68.15 \pm 1.75$ & $176.7 \pm 9.19$ & $71.26 \pm 3.24$ \\
\hline
\end{tabular}

As figure 1 demonstrates, SEM results indicated a uniform spherical shape in the niosome-encapsulated meropenem of F1 formulation with an average size of 51.3 which indicates the suitable diameter $(<100)$ of this drug formulation.

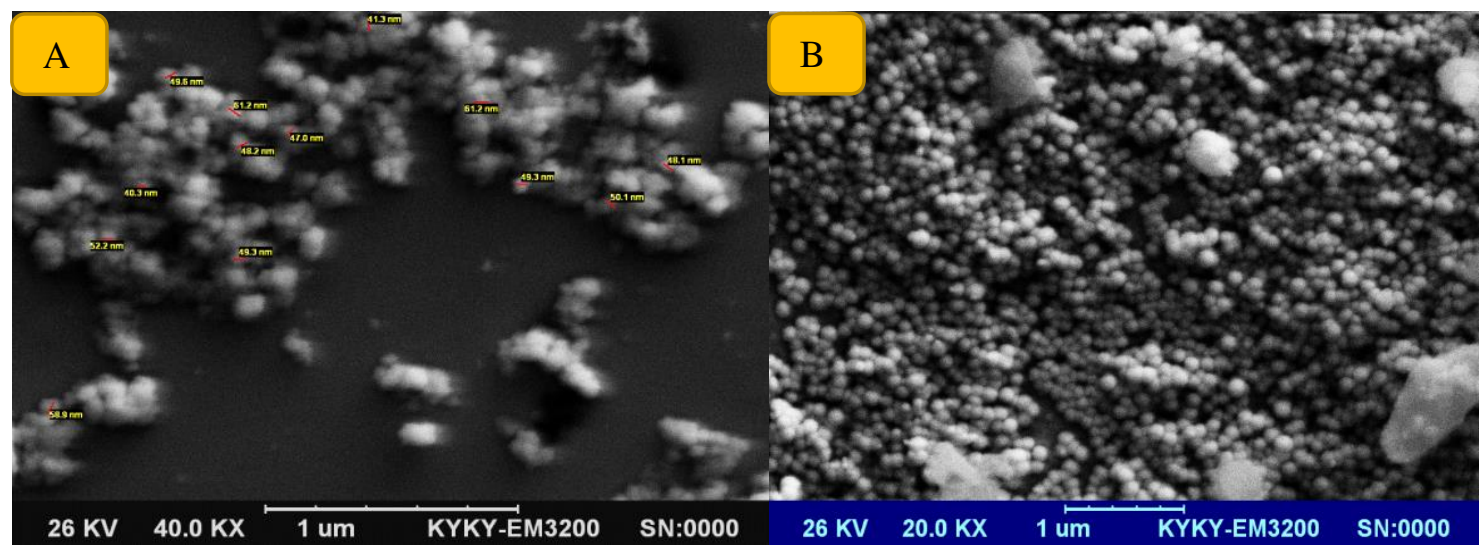

Figure 1.a: niosome-encapsulated meropenem b. the uniform spherical shape of niosome-encapsulated meropenem 
As the diagram resulting from X-ray diffraction indicates (Figure 2), the presence of nanoparticles was confirmed in the $2 \theta$ range in 20-80 degrees. The four diffraction peaks observed in the XRD spectrum of the sample in degrees higher than 37 were associated with reflections (111), (200), (220), and (311) at respective angles of 38.141, 46.251, 64.49 , and $77.57^{\circ}$ confirming the presence of meropenem in niosome particles. A comparison of peak intensities reveals that peak 111 is more intense than the other three. The following formulation is used to measure the size of nanoparticles. $\mathrm{d}, \lambda, \theta$, and $\beta$ represent average particle size, 1.5406 angstrom X-ray wavelength, Bragg's diffraction angle, and full-width-half-Maximum in radians (FWHM). The formulation indicates that the size of the particle measured by XRD is $51.3 \mathrm{~nm}$.

Formula 4: $\quad d=\frac{0.89 \lambda}{\beta \cos \theta}$

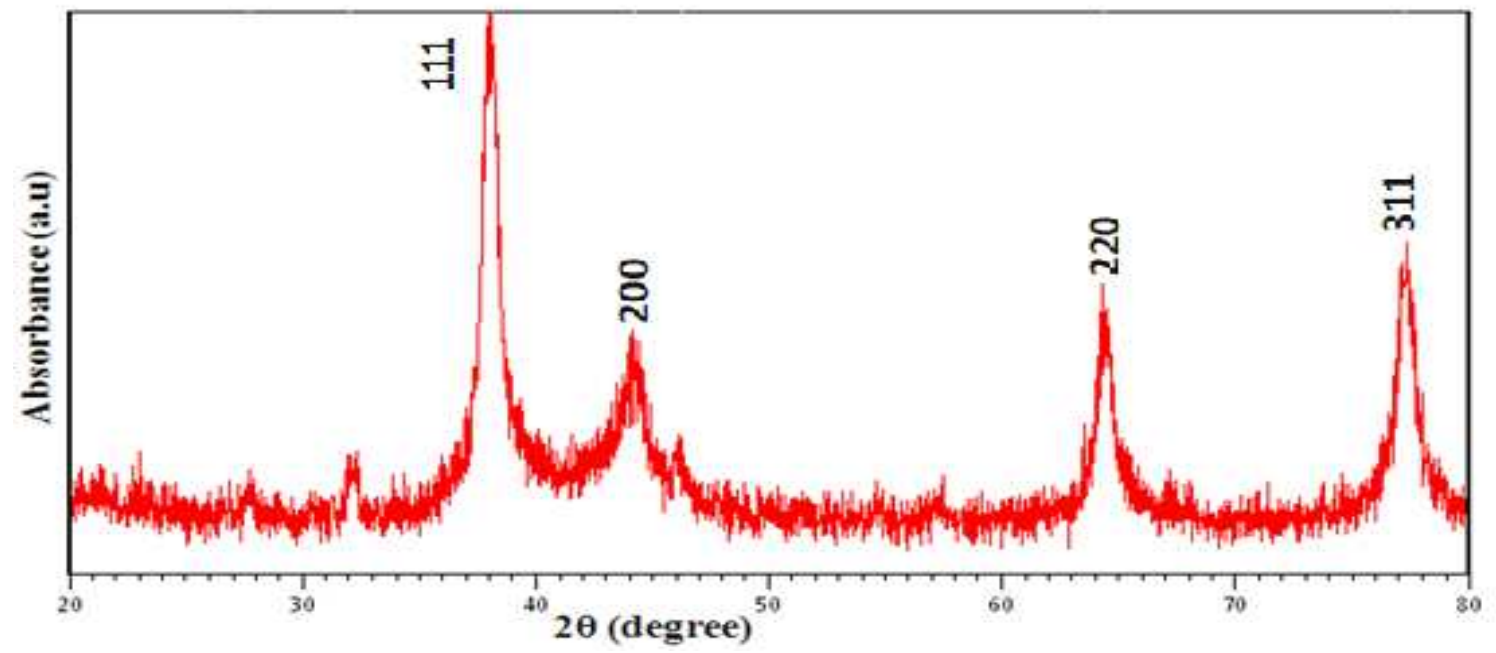

Figure 2: the XRD pattern of niosome-encapsulated meropenem

The amount of meropenem released from the niosome was examined using the dialysis bag method. Meropenem's antibiotic release from niosome nanoparticles demonstrated a two-phase release pattern made up of the blast and stable phases so that the stable constant reached its peak after 7 hours in various formulations. The released amount of antibiotic then started declining and the release speed increased with a gentle slope for up to 72 hours. Lower speeds in drug release in the blast phase were associated with higher encapsulation efficiency and more effective controlled drug release. Therefore, the highest efficiencies of controlled emission were attributed to formulations F1, F3, F4, and F2 with respective release percentages of $45,48,52$, and 56 in the blast phase. The F1 formulation had the highest efficiency in controlled diffusion, showing a 98.2\% drug release after 312 hours while free meropenem's drug release was $89 \%$ in the blast phase which increased to $99 \%$ in 72 hours (Figure 3). 


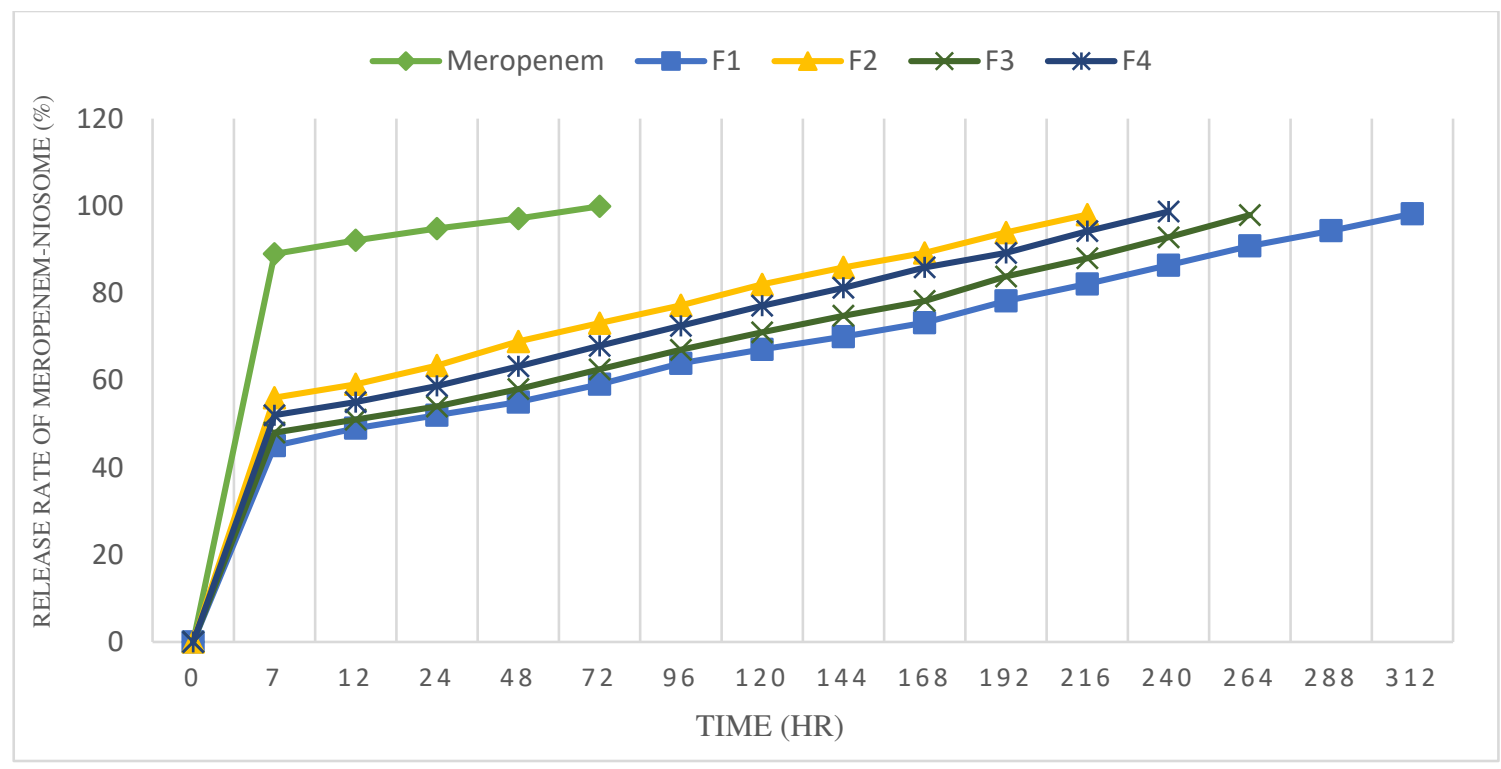

Figure 3: the rate of controlled drug release in various formulations of niosome-encapsulated meropenem compared to free meropenem.

Morphologic features of niosome-encapsulated meropenem such as average size and encapsulation efficiency (EE) were examined to evaluate its stability in various temperatures and time intervals. Results indicated that temperature increase changes the morphological features of niosome-encapsulated meropenem and increased its size, resulting in decreased drug EE while increasing shelf life did not leave any significant effects on its EE and morphological features (Figure 4). According to results, various drug formulations had higher stability at $4{ }^{\circ} \mathrm{C}$ compared to $25^{\circ} \mathrm{C}$, indicating the negative impact of temperature on encapsulated drug's stability. On the other hand, the F1 formulation of niosomeencapsulated meropenem was the most stable among the formulas.

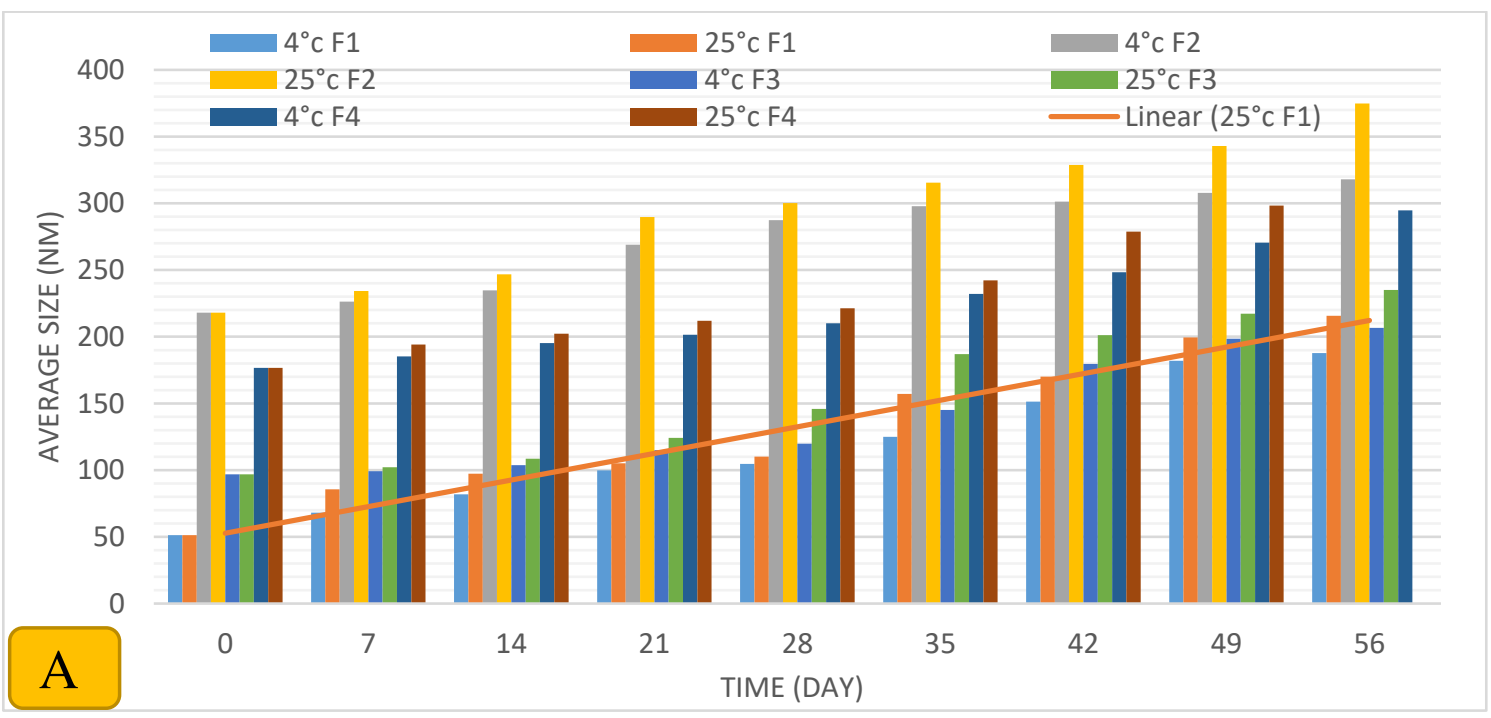




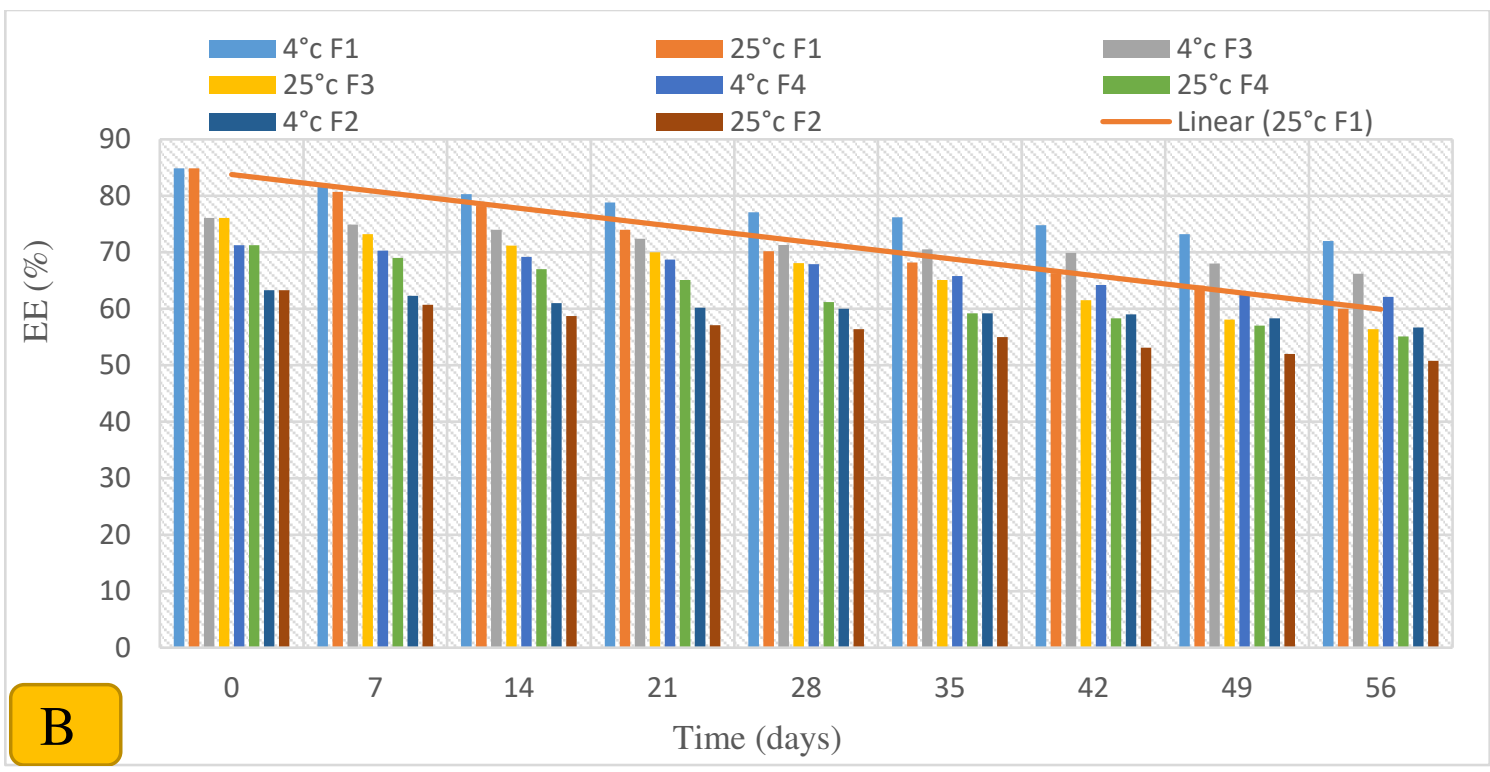

Figure 4: the impact of temperature and shelf time on average size (A) and encapsulation efficiency (B) of niosome-encapsulated meropenem

To examine the antibacterial features of MIC, MBC, and sub-MIC niosome-encapsulated meropenem, two drugs of free meropenem and various formulations of niosome-encapsulated meropenem were tested against 6 MDR S. aureus (that were resistant to vancomycin and methicillin) such as $\mathrm{S}_{\mathrm{MRSA}} 1, \mathrm{~S}_{\mathrm{MRSA}} 2, \mathrm{~S}_{\mathrm{MRSA}} 3, \mathrm{~S}_{\mathrm{MRSA}} 4, \mathrm{~S}_{\mathrm{MRSA}} 5$, and $\mathrm{S}_{\mathrm{MRSA}} 6$ as well as S. aureus ATCC 33592 and results were recorded in Table 4. MIC values for free meropenem range between 4-8 $\mu \mathrm{g} / \mathrm{ml}$ to which the aforementioned strains indicated various degrees of resistance. Besides, MBC values did not indicate significant differences with MIC values. The anti-biofilm activity the anti-biofilm activity of niosomeencapsulated meropenem compared to free meropenem was also examined through MBIC. However, among all the examined samples, the F1 formulation decreased the amount of niosome-encapsulated meropenem by 4-6 times the MBIC in comparison with free meropenem. Other formulations of niosome-encapsulated meropenem (F2, F3, and F4) indicated other MIC, MBC, and MBIC degrees. On the other hand, free meropenem indicated no lethal effect or growth inhibition in any of the aforementioned concentration.

Table 4: values of MIC, MBC, and MBIC in various niosome-encapsulated meropenem formulations and free meropenem against resistant S. aureus strains

\begin{tabular}{|c|c|c|c|c|c|c|c|c|c|c|c|}
\hline \multirow{2}{*}{$\begin{array}{c}\text { Bacterial } \\
\text { strain }\end{array}$} & \multicolumn{4}{|c|}{ Pathogenic factors } & \multicolumn{3}{|c|}{ Free Meropenem } & \multicolumn{4}{|c|}{ Encapsulated Meropenem } \\
\hline & $\begin{array}{c}\text { Biofilm } \\
\text { Phenotype }\end{array}$ & MRSA & MDR & $\begin{array}{c}\text { VanB } \\
\text { Resistance } \\
\text { Gene }\end{array}$ & $\begin{array}{c}\mathrm{MIC} \\
(\mu \mathrm{g} / \mathrm{ml})\end{array}$ & $\begin{array}{c}\mathrm{MBC} \\
(\mu \mathrm{g} / \mathrm{ml})\end{array}$ & $\begin{array}{c}\text { MBIC } \\
(\mu \mathrm{g} / \mathrm{ml})\end{array}$ & Formulation & $\begin{array}{c}\text { MIC } \\
(\mu \mathrm{g} / \mathrm{ml})\end{array}$ & $\begin{array}{c}\text { MBC } \\
(\mu \mathrm{g} / \mathrm{ml})\end{array}$ & $\begin{array}{c}\text { MBIC } \\
(\mu \mathrm{g} / \mathrm{ml})\end{array}$ \\
\hline \multirow{4}{*}{$\mathrm{S}_{\mathrm{MRSA}} 1$} & \multirow{4}{*}{ Strong } & \multirow{4}{*}{+} & \multirow{4}{*}{+} & \multirow{4}{*}{+} & \multirow{4}{*}{4} & \multirow{4}{*}{8} & \multirow{4}{*}{2} & F1 & 0.25 & 0.50 & 0.125 \\
\hline & & & & & & & & $\mathrm{F} 2$ & 1.0 & 2.0 & 0.50 \\
\hline & & & & & & & & F3 & 0.5 & 1.0 & 0.25 \\
\hline & & & & & & & & F4 & 1.0 & 1.0 & 0.50 \\
\hline \multirow[b]{2}{*}{ S MRSA 2} & \multirow[b]{2}{*}{ Strong } & \multirow[b]{2}{*}{+} & \multirow[b]{2}{*}{+} & \multirow[b]{2}{*}{+} & \multirow[b]{2}{*}{4} & \multirow[b]{2}{*}{4} & \multirow[b]{2}{*}{2} & $\mathrm{~F} 1$ & 0.125 & 0.25 & 0.062 \\
\hline & & & & & & & & $\mathrm{F} 2$ & 0.50 & 1.0 & 0.25 \\
\hline
\end{tabular}




\begin{tabular}{|c|c|c|c|c|c|c|c|c|c|c|c|}
\hline & & & & & & & & $\mathrm{F} 3$ & 0.125 & 0.25 & 0.125 \\
\hline & & & & & & & & $\mathrm{F} 4$ & 0.25 & 0.50 & 0.125 \\
\hline \multirow{4}{*}{$\mathrm{S}_{\mathrm{MRSA}} 3$} & \multirow{4}{*}{ Strong } & \multirow{4}{*}{+} & \multirow{4}{*}{+} & \multirow{4}{*}{+} & \multirow{4}{*}{8} & \multirow{4}{*}{16} & \multirow{4}{*}{4} & $\mathrm{~F} 1$ & 0.25 & 0.50 & 0.125 \\
\hline & & & & & & & & $\mathrm{F} 2$ & 2.0 & 4 & 1.0 \\
\hline & & & & & & & & $\mathrm{F} 3$ & 0.50 & 1.0 & 025 \\
\hline & & & & & & & & $\mathrm{F} 4$ & 1.0 & 2.0 & 0.50 \\
\hline \multirow{4}{*}{$\mathrm{S}_{\mathrm{MRSA}} 4$} & \multirow{4}{*}{ Strong } & \multirow{4}{*}{+} & \multirow{4}{*}{+} & \multirow{4}{*}{+} & \multirow{4}{*}{2} & \multirow{4}{*}{4} & \multirow{4}{*}{2} & $\mathrm{~F} 1$ & 0.125 & 0.25 & 0.125 \\
\hline & & & & & & & & $\mathrm{F} 2$ & 1.0 & 1.0 & 0.50 \\
\hline & & & & & & & & F3 & 0.25 & 0.50 & 0.125 \\
\hline & & & & & & & & $\mathrm{F} 4$ & 0.50 & 1.0 & 0.25 \\
\hline \multirow{4}{*}{ SMRSA } & \multirow{4}{*}{ Strong } & \multirow{4}{*}{+} & \multirow{4}{*}{+} & \multirow{4}{*}{+} & \multirow{4}{*}{8} & \multirow{4}{*}{8} & \multirow{4}{*}{4} & $\mathrm{~F} 1$ & 0.50 & 1.0 & 0.25 \\
\hline & & & & & & & & $\mathrm{F} 2$ & 2.0 & 4.0 & 1.0 \\
\hline & & & & & & & & F3 & 1.0 & 2.0 & 0.50 \\
\hline & & & & & & & & $\mathrm{F} 4$ & 1.0 & 2.0 & 1.0 \\
\hline \multirow{4}{*}{$\mathrm{S}_{\mathrm{MRSA}} 6$} & \multirow{4}{*}{ Strong } & \multirow{4}{*}{+} & \multirow{4}{*}{+} & \multirow{4}{*}{+} & \multirow{4}{*}{4} & \multirow{4}{*}{8} & \multirow{4}{*}{4} & $\mathrm{~F} 1$ & 0.125 & 0.25 & 0.062 \\
\hline & & & & & & & & $\mathrm{F} 2$ & 2.0 & 2.0 & 1.0 \\
\hline & & & & & & & & F3 & 0.25 & 0.50 & 0.125 \\
\hline & & & & & & & & $\mathrm{F} 4$ & 0.50 & 1.0 & 0.25 \\
\hline & & & & & & & & $\mathrm{F} 1$ & 0.125 & 0.25 & 0.125 \\
\hline ATCC & Moderate & + & + & - & 2 & 4 & 2 & $\mathrm{~F} 2$ & 1.0 & 2.0 & 0.50 \\
\hline 33592 & & & & & & & & F3 & 0.125 & 0.25 & 0.062 \\
\hline & & & & & & & & $\mathrm{F} 4$ & 0.50 & 1.0 & 0.25 \\
\hline
\end{tabular}

Out of the examined bacterial strains, the six isolates of $\mathrm{SM}_{\mathrm{RSA}} 1, \mathrm{~S}_{\mathrm{MRSA}} 2, \mathrm{~S}_{\mathrm{MRSA}} 3, \mathrm{~S}_{\mathrm{MRSA}} 4, \mathrm{~S}_{\mathrm{MRSA}} 5$ and $\mathrm{S}_{\mathrm{MRSA}} 6$ as well as the standard S. aureus ATCC 33592 isolate were selected as biofilm-generating strains, and the ability of niosomes carrying meropenem in inhibiting the growth of resistant Staphylococcus isolates through adhesion to biofilm over a short period of being exposed to drug formulations was compared to that of free meropenem. Compared to the minimum biofilm inhibitory concentration (MBIC) study, biofilm growth inhibition condition was harder since biofilm was first treated for only two hours with drug formulations or free meropenem; biofilms were then washed and incubated in an anti-biotic free medium for 24 hours. This study was conducted in concentrations ranging from 1.2-2MIC for respective isolates. The concentration of drug formulations compared to free meropenem MIC was calculated for physical composition and results were reported as Biofilm Growth Inhibition percentage (BIG\%, Figure 5). 


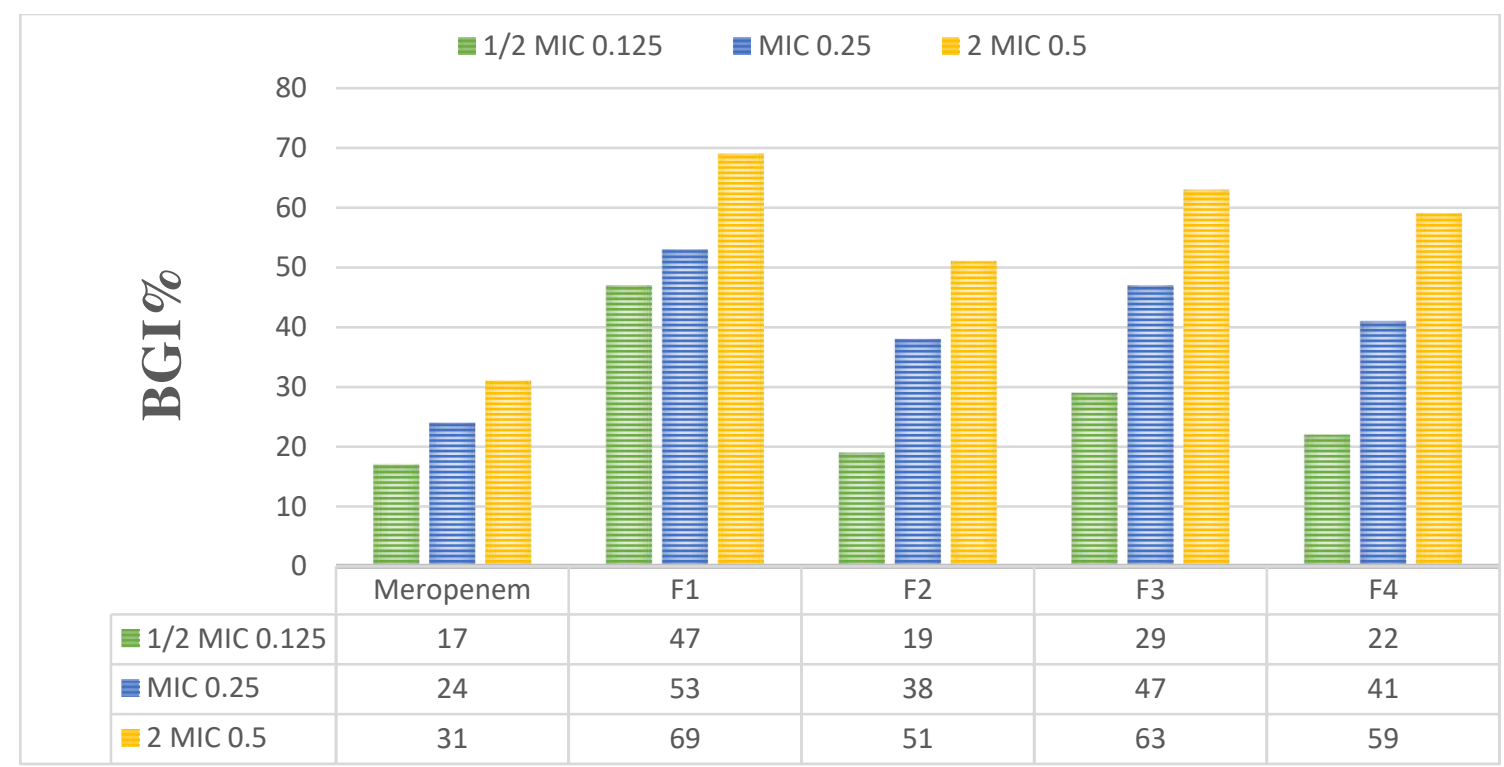

Figure 5: biofilm growth inhibition percentage of various formulations of niosome-encapsulated Meropenem

Afterward, the subMIC concentrations of niosome-encapsulated meropenem were used to examine anti-biofilm activity, and the expression of biofilm genes icaD, FnbA, Ebps, and Bap in bacteria was examined through Quantitative Real-Time PCR. Results obtained from genes' expressions to 16SrRNA reference gene in positive biofilm strains were recorded and demonstrated in Figures 6A and 6B before treatment with the drug, after treatment with free meropenem, and after treatment with niosome-encapsulated meropenem. According to results, the highest decline in the expression of genes icaD, FnbA, Ebps, and Bap revealed to be after treatment with niosomeencapsulated meropenem $(\mathrm{P} \leq 0.05)$. Besides, the $\mathrm{F} 1$ formulation had the highest efficiency among the drug formulations. 

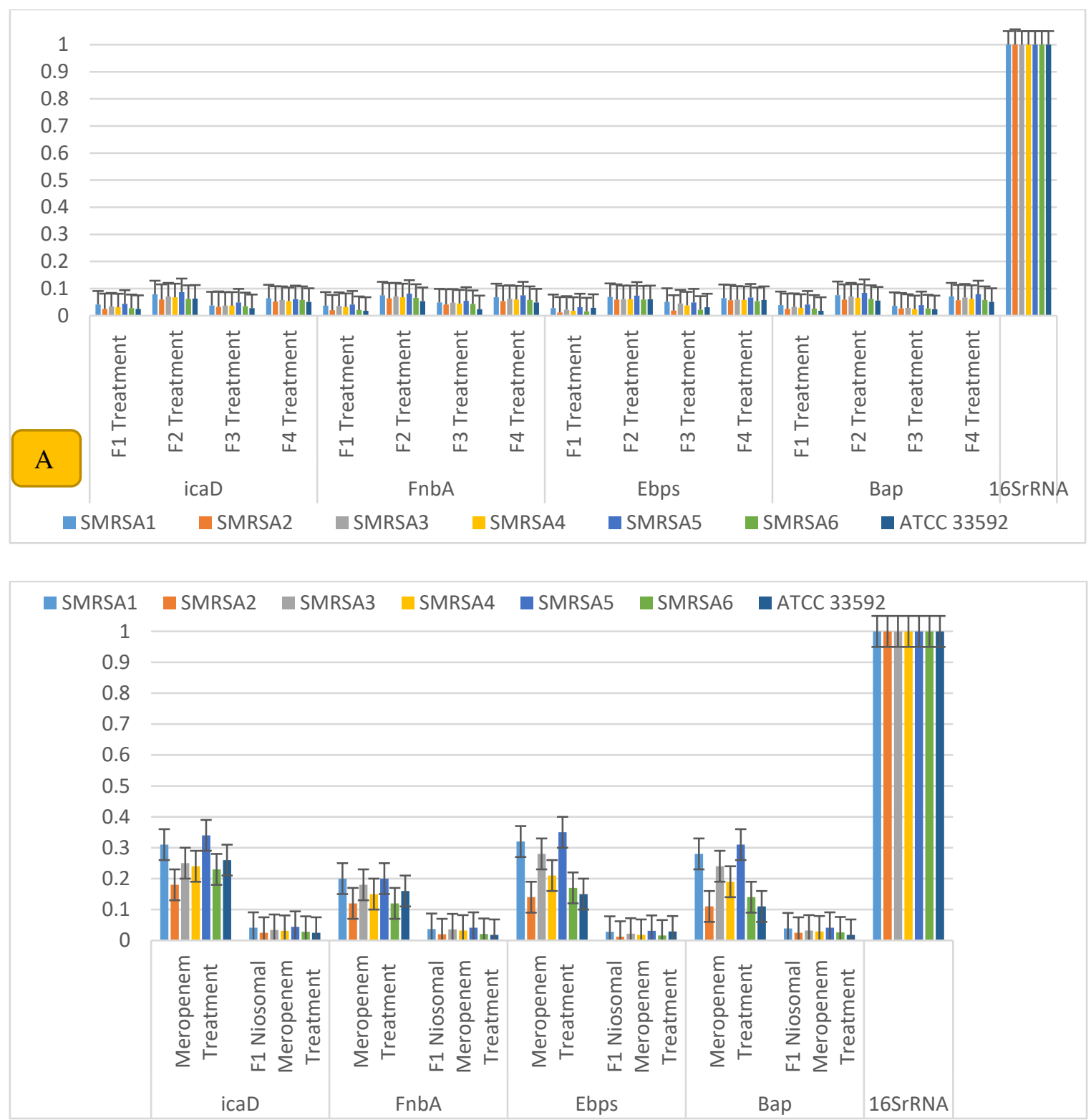

Figure 6.A. effect of various drug formulations on biofilm gene expressions B. effect of the best drug formulation (F1) on biofilm gene expression compared to free meropenem before and after treatment

Eventually, the cytotoxicity of various drug formulations was compared to that of free meropenem on the HDF cell line. Niosome-encapsulated indicated a considerably higher cell viability rate compared to free meropenem in all tested concentrations. Almost $68 \%$ of the cells survived for 24 hours after being treated with $256 \mu \mathrm{M}$ meropenem while over $90 \%$ of cells survived for 24 hours after being incubated with the F1 formulation of niosome-encapsulated meropenem. Cell viability was $75 \%, 86 \%$, and $79 \%$, for the respective formulations of F2, F3, and F4 at $256 \mu \mathrm{M}$ (Figure 7). 


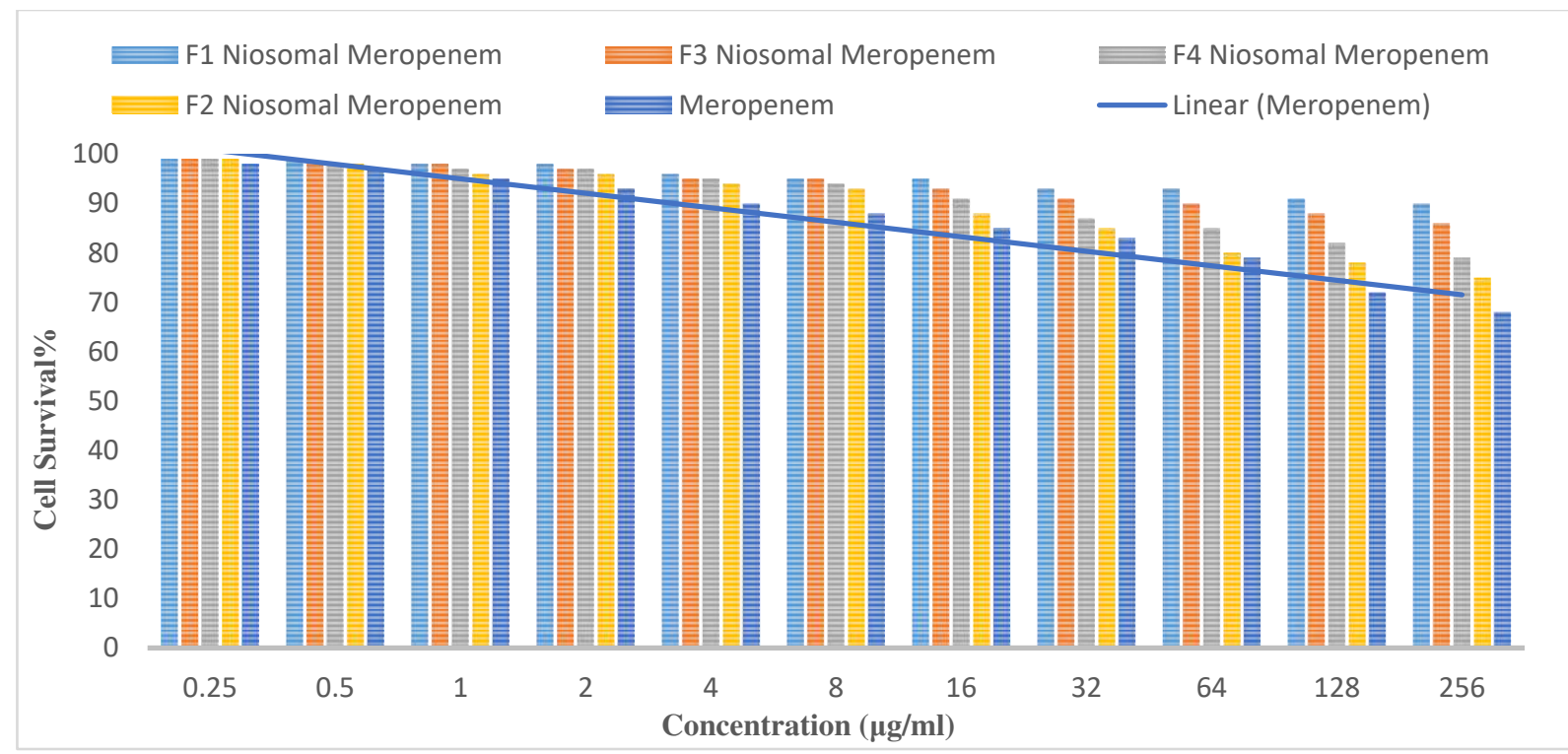

Figure 7: cell viability percentage of HDF cells treated with various formulations of niosome-encapsulated meropenem in comparison with free niosome over 24 hours

4. Discussion and conclusion

Methicillin-resistant Staphylococcus aureus (MRSA) is among prevalent hospital pathogens whose prevalence has been increased all over the world over the past three decades and has posed serious threats as a nosocomial infection (31). Hence, examining this pathogen's prevalence in samples taken from three hospitals including Shariati, Firouzgar, and Rasoul Akram indicated a 54\% Staphylococcus aureus prevalence. On the other hand, Staphylococcus aureus (MRSA) bacteria demonstrate resistance to a variety of antibiotics to a point that some of its strains have indicated vancomycin-resistance (32). The present study examined the sensitivity of various isolates, indicating that 82.71 of the isolates were MDR and $82.07 \%$ of the strains were vancomycin-resistant while vancomycin is among the drug choices to MSRA, which was consistent with previous research (33). Besides, $72.38 \%$ of the isolates were capable of forming biofilms which are among the main factors of microbial resistance among Iranian nosocomial infections according to Piri et al. $(2018,17)$. According to the literature, the formation of biofilm in S. aureus reduces the speed of antibiotics' penetration and causes complications for the treatment of infections due to these bacteria (33). Therefore, research focused on new treatment strategies as well as strategies for reducing MRSA resistance is of great importance. Given that niosome formulations are being studied as promising tools to increase compounds' antibacterial activities (34), the present study focused on niosome-encapsulated meropenem to reduce the resistance of MRSA and increase antibacterial activity against it. Various synthesized formulations were prepared including Tween 60 and 
Tween 40 non-ionic surfactants as well as Span 60 and Span 40 mixed with cholesterol. Given that various cholesterol levels could result in various bilayers in formulations and impact bilayers' surface load, its amount was kept steady across all formulations. Therefore, the niosome membrane's strength and resistance to ultrasound waves were kept constant across all formulations by keeping the cholesterol constant which resulted in more uniform vesicles in terms of size (35). On the other hand, various surfactant combinations resulted in nanostructures with various morphological features (36). The use of equal Tween and Span ratios resulted in different results. Tween 60 results in reduced niosome membrane strength because of its high hydrophilicity (37). This defect was resolved by adding equal Span 60 surfactant (50:50) which is more hydrophobic and resulted in the formation of dense niosome films. On the other hand, Tween 60 and Span 60 have higher phase transfer temperatures compared to other surfactants used in the study, which results in increased drug encapsulation (38). Span60's long saturated alkyl chain resulted in more preamble niosomes as an influential factor, resulting in multiplied drug encapsulation (39). Besides, Span60 surfactant has a lipophilic balance of 4.7 which is lower than that of Span40 (6.7), resulting in the formation of smaller vesicles (40). Therefore, the F1 formulation was revealed to have a more suitable size and morphological features compared to other formulations. The Span40 used in F2, F3, and F4 formulations resulted in larger vesicles compared to that of F1 due to their high hydrophilic-lipophilic balance. On the other hand, formulations F2, F3, and F4 contained less encapsulated drugs despite their larger size due to Span40's unsaturated alkyl chain, resulting in their lower Encapsulation Efficiency (EE). Besides, Formulations F2, F3, and F4 had lower phase transfer temperatures and weaker wall strength due to the presence of Tween 60 and Tween 40 surfactants, which results in the formation of a thin structure and low encapsulation efficiency. Hence, the size obtained for the F1 formulation was quite smaller than the other three, indicating this formulation's higher EE. Hedayati et al. (2020) examined various niosome-encapsulated meropenem formulations, reporting that the size of niosome-encapsulated meropenem varied across different formulations (41). This study's controlled drug release profile indicate a biphasic pattern. Given the niosome bilayer structure, the drug might reside either in the center of the niosome within the two layers or at the surface of the niosome during encapsulation (42). Therefore, the drugs on the surface start being released over the first hours of release which results in the blast phase (fast drug release). After seven hours, surface drugs will have released and encapsulated drugs residing at the center of the niosome and on the bilayer membrane start being released, resulting in controlled drug released and the stable phase. On the other hand, the cholesterol present in the system stops the gel to lipid phase transfer in niosome systems which prevents the drug from leaking out of the niosomes, resulting in controlled drug 
released over the long term and longer efficient drug release (43). Because of its higher strength as well as good surface density, formulation F1 forms better links with cholesterol, resulting in a reduced drug delivery process. Figure 3 indicates that this formulation has the longest time possible for controlled drug release ( 312 hours). Besides, negative zeta potentials are because of the electrostatic repulsion between the particles according to previous research, resulting in higher niosome stability (44). Studying the values of zeta potential and stability revealed that formulation F1 had the most stable niosome-encapsulated-meropenem with a zeta potential of $-65.29 \pm 2.68$ over 56 days at $4{ }^{\circ} \mathrm{C}$ and $25^{\circ} \mathrm{C}$ among the formulations studied. Additionally, drug stability was higher at $4{ }^{\circ} \mathrm{C}$ compared to $25^{\circ} \mathrm{C}$, which might be due to lower niosome bilayer mobility at $4^{\circ} \mathrm{C}(45)$. As a negative factor, the time of drug immobility has a direct relationship with nanoparticle size and an inverse relationship with EE index. Longer drug immobility time results in larger nanoparticle size due to particles' accumulation or fusion, and the pressure resulting from nanoparticle accumulation on niosome bilayer might result in the diffusion of the layers and reduction in their EE (46). The present study mainly aimed to improve the antibacterial features of niosome-encapsulated meropenem. Hence, antibacterial assays were conducted after isolation and determining the prevalence and resistant strains. Niosome-encapsulated meropenem's MIC was much lower than free meropenem, indicating the drug's increased efficiency and antibacterial activity and bacteria's lower drug resistance. Heba et al (2014) suggested that loading vancomycin in the niosome improves its anti-biofilm and antibacterial activity and efficiency against Staphylococcus (47). Numerous studies have reported niosome's potentials in increasing antibiotics' antibacterial activity through targeted drug delivery and protecting antibiotics from unfavorable environmental conditions $(48,49)$. Phikunthong et al. (2011) reported niosome's great potential to encapsulate niacin and improve its antibacterial activity (50). Tinnakorn et al. (2017) reported that the cholesterol existing in niosome results in increased targeted drug delivery to bacteria through binding to bacteria's lipid membrane (52). Consistent with that of Machado and Akbari, results of the present study indicate increased antibacterial activity in nanomaterial-encapsulated antibiotics (53, 54). According to Gupta et al. (2018), there are various absorption and fusion mechanisms between the niosome and the bacterial wall that could result in increased targeted drug delivery (55). The other aim of the present study was to examine niosome-encapsulated meropenem's anti-biofilm features in the form of biofilm formation inhibition, biofilm growth inhibition, and prevention or reduction of biofilm-involved gene's expression. Niosome-encapsulate meropenem's MBIC was four to six times free meropenem in all the studied isolates, indicating the higher efficiency of nanoparticles compared to free drug. On the other hand, the F1 formulation of niosome-encapsulate meropenem indicated the highest biofilm 
formation and growth inhibition. A variety of studies have suggested a direct relationship between reduced efficiency of antibacterial materials and the ability to form biofilms (56). Ikonomidis et al. (2009) reported that Staphylococcus aureus MRSA strains with the ability to form biofilm were more antibacterial-resistant than the strains unable to form biofilms (57). Manandhar et al. (2018) reported lower sensitivity and therefore higher antibacterial resistance in clinically isolated Staphylococcus aureus strains that could form biofilms compared to those that couldn't (58). Most of the time, patients might refer to the hospital when the bacteria are in advanced stages and have already formed biofilm structures, in which case most antibiotics would be ineffective (59). Biofilm growth is a significant factor in increased bacterial resistance (60). Therefore, preventing biofilm growth was the key objective of this study. 1 MIC, 1/2 MIC, and 2MIC concentrations of various formulations of niosome-encapsulated meropenem and free meropenem were prepared and the ability to inhibit biofilm growth after two hours of being treated with drugs over 24 hours demonstrated biofilm growth and maturation inhibition. Formulation F1of niosome-encapsulated meropenem indicated the best performance in biofilm growth inhibition, indicating the impact of antibiotics' encapsulation on their increased efficiency and biofilm growth inhibition which is consistent with the results of Barakat et al. (2014, 61). Recently, several studies have reported a direct relationship between biofilm gene expressions and increased microbial resistance in Staphylococcus aureus MRSA strains $(62,63)$. Hence, the present study examined the impact of niosome-encapsulated meropenem sub-MIC concentration on icaD, FnbA, Ebps, and Bap biofilm genes, revealing a considerable decline in the expression of these genes compared to free meropenem. Besides, the F1 formulation had the highest impact on reducing gene expression and was therefore identified to be the optimal formulation. Reducing the expression of the aforementioned genes could result in the inhibition of transcription through a direct impact and cause a reaction between niosome-encapsulated meropenem and transcription factors which will result in the inhibition or reduction of such genes' expression. These results are consistent with that of Lawson et al. (2012), revealing that the impact of Nano-encapsulation on increasing the inhibition of biofilms and reducing biofilm gene expressions (64). The exopolysaccharide matrix of biofilm is the main source of defense and resistance against direct contact between Staphylococcus aureus and antibacterial agents (65). Results of this study revealed that the formulation of niosomeencapsulated meropenem reduces the resistance of Staphylococcus aureus MDR bacteria through biofilm growth inhibition and resulted in increased antibacterial properties for meropenem as well as being able to reduce biofilm gene expressions and prevent the growth of biofilm. Abdelazizi et al. suggested that niosome-encapsulation of norfloxacin improves its anti-biofilm properties and MDR bacteria biofilm formation (66). The increased microbial 
resistance to various antibiotics had highlighted the need for finding new antibacterial compounds that are non-toxic for mammalian cells (67). The present study examined the toxicity of various niosome-encapsulated meropenem formulations for HDF cells through the standard method of MTT, indicating a higher cell viability rate in groups treated with niosome-encapsulated meropenem compared to free meropenem. Formulation F1 of niosomeencapsulated meropenem indicated the lowest cytotoxicity compared to other formulations with cell viability of over 90\% over 24 hours. These formulations' cytotoxicity was due to the use of various Span: Tween surfactant ratios with high biodegradability, making these formulations suitable candidates for encapsulating meropenem as well as other drugs (68).

General conclusion

Niosome-encapsulated meropenem is a new approach for restoring meropenem characteristics with a low cost, giving meropenem distinct new properties such as increased targeted drug delivery, maintaining stability, and controlling drug release. According to this study, this drug formulation is more effective than free meropenem in treating infections due to more resistant Staphylococcus aureus isolates that are resistant to a variety of antibiotics, especially vancomycin and methicillin, and the present study is the first to report the impacts of encapsulating meropenem in niosome on biofilm formation and growth inhibition, biofilm eradication, and distinct antimicrobial activity against MRSA clinical isolates. As a general result, nisosmes are promising new drug systems increasing drugs' antibacterial effects whose antibacterial features depend on their formulation and composition. According to the present study's results, it could be inferred that niosome-encapsulation of meropenem increases its antibacterial and anti-biofilm activities against MDR and MRSA S. aureus strains and these formulations could be considered a new strategy for targeted drug delivery. 


\section{LIST OF ABBREVIATIONS}

\begin{tabular}{|c|c|c|}
\hline Polydispersity index & $=$ & PDI \\
\hline Entrapment efficiency & $=$ & $\mathrm{EE}$ \\
\hline Dynamic Light Scattering & $=$ & DLS \\
\hline Methicillin-resistant Staphylococcus aureus & $=$ & MRSA \\
\hline Fibronectin & $=$ & Fn \\
\hline Elastin-binding protein & $=$ & EbpS \\
\hline Clinical and Laboratory Standards Institute & $=$ & CLSI \\
\hline Minimum inhibitory concentration & $=$ & $\mathrm{MIC}$ \\
\hline Minimum bactericidal concentration & $=$ & $\mathrm{MBC}$ \\
\hline Minimum Biofilm Inhibition Concentration & $=$ & MBIC \\
\hline Quantitative Real Time PCR & $=$ & qRT-PCR \\
\hline Luria-Bertani & $=$ & LB \\
\hline Methyl Dimethyl-thiazolyldiphenyltetrazolium & $=$ & MTT \\
\hline Dimethyl sulfoxide & $=$ & DMSO \\
\hline
\end{tabular}

\section{Declarations:}

Ethics approval and consent to participate

This study was conducted by observing the ethical principles and regulations approved by Islamic Azad University of Shahrekord Branch, Iran.

\section{CONSENT FOR PUBLICATION}

Not applicable. 


\section{Availability of data and materials}

The authors have no objection to the availability of data and materials freely.

\section{Competing interests}

All authors declare that they have no conflict of interest

\section{Funding}

Funding information is not available.

\section{Authors' contributions}

All authors have participated in this research.

\section{ACKNOWLEDGEMENTS}

The authors would like to thank the staff members of Biotechnology Research Center of Islamic Azad University of Shahrekord Branch in Iran for their help and support. This research did not receive any specific grant from funding agencies in the public, commercial, or not-for-profit sectors.

\section{Authors' information}

Not applicable.

\section{Disclosure}

All authors declare that they have no conflict of interest. 


\section{References}

1. Ansari, Shamshul, et al. "Recent advances in Staphylococcus aureus infection: focus on vaccine development." Infection and drug resistance 12 (2019): 1243.

2. González, Carmen, et al. "Bacteremic pneumonia due to Staphylococcus aureus: a comparison of disease caused by methicillin-resistant and methicillin-susceptible organisms." Clinical Infectious Diseases 29.5 (1999): 1171-1177.

3. Turner, Nicholas A., et al. "Methicillin-resistant Staphylococcus aureus: an overview of basic and clinical research." Nature Reviews Microbiology 17.4 (2019): 203-218.

4. Guo, Yunlei, et al. "Prevalence and Therapies of Antibiotic-Resistance in Staphylococcus aureus." Frontiers in Cellular and Infection Microbiology 10 (2020): 107.

5. Fish, Douglas N. "Meropenem in the treatment of complicated skin and soft tissue infections." Therapeutics and clinical risk management 2.4 (2006): 401.

6. Liebchen, U., et al. "Therapeutic drug monitoring-guided high dose meropenem therapy of a multidrug resistant Acinetobacter baumannii-A case report." Respiratory medicine case reports 29 (2020): 100966.

7. Gonzales, Patrick R., et al. "Synergistic, collaterally sensitive $\beta$-lactam combinations suppress resistance in MRSA." Nature chemical biology 11.11 (2015): 855-861.

8. Elshamy, Ann A., and Khaled M. Aboshanab. "A review on bacterial resistance to carbapenems: epidemiology, detection and treatment options." Future Science OA 6.3 (2020): FSO438.

9. Green, Bart N., et al. "Methicillin-resistant Staphylococcus aureus: an overview for manual therapists." Journal of chiropractic medicine 11.1 (2012): 64-76.

10. Khatoon, Zohra, et al. "Bacterial biofilm formation on implantable devices and approaches to its treatment and prevention." Heliyon 4.12 (2018): e01067.

11. Gebreyohannes, Gebreselema, et al. "Challenges of intervention, treatment, and antibiotic resistance of biofilm-forming microorganisms." Heliyon 5.8 (2019): e02192.

12. Beloin, Christophe, and Jean-Marc Ghigo. "Finding gene-expression patterns in bacterial biofilms." Trends in microbiology 13.1 (2005): 16-19.

13. Nemati, Mostafa, et al. "Screening of genes encoding adhesion factors and biofilm formation in Staphylococcus aureus isolates from poultry." Avian Pathology 38.6 (2009): 513-517.

14. Foster, T. J. "The remarkably multifunctional fibronectin binding proteins of Staphylococcus aureus." European Journal of Clinical Microbiology \& Infectious Diseases 35.12 (2016): 1923-1931.

15. Speziale, Pietro, and Giampiero Pietrocola. "The Multivalent Role of Fibronectin-Binding Proteins A and B (FnBPA and FnBPB) of Staphylococcus aureus in Host Infections." Frontiers in Microbiology 11 (2020): 2054. 
16. Kot, Barbara, Hubert Sytykiewicz, and Iwona Sprawka. "Expression of the biofilm-associated genes in methicillinresistant Staphylococcus aureus in biofilm and planktonic conditions." International journal of molecular sciences 19.11 (2018): 3487.

17. Piri Gharaghie, Tohid, and Seyed Ataollah Sadat Shandiz. "The Inhibitory Effects of Silver Nanoparticles on Bap Gene Expression in Antibiotic-Resistant Acientobacter bumanni Isolates using Real-Time PCR." scientific journal of ilam university of medical sciences 26.4 (2018): 175-185.

18. Vazquez-Muñoz, R., et al. "Enhancement of antibiotics antimicrobial activity due to the silver nanoparticles impact on the cell membrane." PloS one 14.11 (2019): e0224904.

19. Martin-Serrano, Ángela, et al. "Nanosystems as vehicles for the delivery of antimicrobial peptides (AMPs)." Pharmaceutics 11.9 (2019): 448.

20. Becerril, Raquel, Cristina Nerín, and Filomena Silva. "Encapsulation Systems for Antimicrobial Food Packaging Components: An Update." Molecules 25.5 (2020): 1134.

21. Ge, Xuemei, et al. "Advances of non-ionic surfactant vesicles (niosomes) and their application in drug delivery." Pharmaceutics 11.2 (2019): 55.

22. Yeo, Pei Ling, et al. "Niosomes: a review of their structure, properties, methods of preparation, and medical applications." Asian Biomedicine 11.4 (2018): 301-314.

23. Durak, Saliha, et al. "Niosomal Drug Delivery Systems for Ocular Disease-Recent Advances and Future Prospects." Nanomaterials 10.6 (2020): 1191.

24. Tiwari HK, Sen MR. Emergence of vancomycin resistant Staphylococcus aureus (VRSA) from a tertiary care hospital from northern part of India. BMC infect dis 2006; 6:156

25. Xu, Ying-Qi, et al. "Niosome encapsulation of curcumin: characterization and cytotoxic effect on ovarian cancer cells." Journal of Nanomaterials 2016 (2016).

26. Abdelbary, Ghada, and Nashwa El-gendy. "Niosome-encapsulated gentamicin for ophthalmic controlled delivery." AAPS pharmscitech 9.3 (2008): 740-747.

27. Vyas SP, Sihorkar V, Jain S. Mannosylated liposomes for bio-film targeting. Int J Pharm. 2007; 330(1-2):6-13.

28. Cianfruglia, Laura, et al. "Side effects of curcumin: Epigenetic and antiproliferative implications for normal dermal fibroblast and breast cancer cells." Antioxidants 8.9 (2019): 382.

29. Riss, Terry L., et al. "Cell viability assays assay guidance manual." Assay Guidance Manual (2004): 1-23.

30. Li, Weijia, Jing Zhou, and Yuyin Xu. "Study of the in vitro cytotoxicity testing of medical devices." Biomedical reports 3.5 (2015): 617-620.

31. Siddiqui, Abdul H., and Janak Koirala. "Methicillin Resistant Staphylococcus aureus." StatPearls [internet] (2018). 
32. Rahimi, Fateh, et al. "Antibiotic resistance pattern of methicillin resistant and methicillin sensitive Staphylococcus aureus isolates in Tehran, Iran." (2013): 144-149.

33. Bissong, Marie Ebob Agbortabot, and Collins Njie Ateba. "Genotypic and Phenotypic Evaluation of Biofilm Production and Antimicrobial Resistance in Staphylococcus aureus Isolated from Milk, North West Province, South Africa." Antibiotics 9.4 (2020): 156.

34. Muzzalupo, Rita, and Lorena Tavano. "Niosomal drug delivery for transdermal targeting: recent advances." Research and reports in transdermal drug delivery 4 (2015): 23.

35. Sadeghi S, Bakhshandeh H, Ahangari Cohan R, Peirovi A, Ehsani P, Norouzian D. Synergistic anti-staphylococcal activity of niosomal recombinant lysostaphin-LL-37. Int J Nanomedicine. 2019; 14: 97779792.

36. Wei, Wenbo, Feng Bai, and Hongyou Fan. "Surfactant-assisted cooperative self-assembly of nanoparticles into active nanostructures." IScience 11 (2019): 272-293.

37. Moazeni E, Gilani K, Sotoudegan F, et al. Formulation and in vitro evaluation of ciprofloxacin containing niosomes for pulmonary delivery. J Microencapsul. 2010; 27: 618-627.

38. Akbari, Vajihe, et al. "Release studies on ciprofloxacin loaded non-ionic surfactant vesicles." Avicenna journal of medical biotechnology 7.2 (2015): 69.

39. Hao Y, Zhao F, Li N, Yang Y, Li K. Studies on a high encapsulation of colchicine by a niosome system. Int J Pharm. 2002; 244(1-2):73-80. doi: 10.1016/S0378-5173(02)00301-0

40. Aziz, Diana E., Aly Ahmed Abdelbary, and Abdelhalim Ibrahim Elassasy. "Implementing central composite design for developing transdermal diacerein-loaded niosomes: ex vivo permeation and in vivo deposition." Current drug delivery 15.9 (2018): 1330-1342.

41. Hedayati Ch, Mojtaba, et al. "Niosome-encapsulated tobramycin reduced antibiotic resistance and enhanced antibacterial activity against multidrug-resistant clinical strains of Pseudomonas aeruginosa." Journal of Biomedical Materials Research Part A (2020).

42. Kazi, Karim Masud, et al. "Niosome: a future of targeted drug delivery systems." Journal of advanced pharmaceutical technology \& research 1.4 (2010): 374.

43. Balasubramaniam A, Kumar VA, Pillai KS. Formulation and in vivo evaluation of niosome-encapsulated daunorubicin hydrochloride. Drug Dev Ind Pharm. 2002; 28: 1181-1193.

44. Barakat HS, Kassem MA, El-Khordagui LK, Khalafallah NM. Vancomycin-eluting niosomes: a new approach to the inhibition of staphylococcal biofilm on abiotic surfaces. AAPS PharmSciTech. 2014; 15(5):1263-1274. doi: $10.1208 / \mathrm{s} 12249-014-0141-8$ 
45. Barakat HS, Kassem MA, El-Khordagui LK, Khalafallah NM. Vancomycin-eluting niosomes: a new approach to the inhibition of staphylococcal biofilm on abiotic surfaces. AAPS Pharm Sci Tech. 2014; 15(5):1263-1274.

46. Derbali RM, Aoun V, Moussa G, et al. Tailored nanocarriers for the pulmonary delivery of levofloxacin against Pseudomonas aeruginosa: a comparative study. Mol Pharm. 2019; 16(5):1906-1916.

47. Barakat, Heba S., et al. "Vancomycin-eluting niosomes: a new approach to the inhibition of staphylococcal biofilm on abiotic surfaces." AAPS PharmSciTech 15.5 (2014): 1263-1274.

48. Wang, Linlin, Chen Hu, and Longquan Shao. "The antimicrobial activity of nanoparticles: present situation and prospects for the future." International journal of nanomedicine 12 (2017): 1227.

49. Gritsch, Lukas. "An investigation on antibiotic-free antibacterial materials combining bioresorbable polyesters, chitosan and therapeutic ions." (2019).

50. Kopermsub, Phikunthong, Varissaporn Mayen, and Choochart Warin. "Potential use of niosomes for encapsulation of nisin and EDTA and their antibacterial activity enhancement." Food Research International 44.2 (2011): 605-612.

51. Theansungnoen, Tinnakorn, et al. "FORMULATION AND EVALUATION OF NIOSOMES ENCAPSULATED WITH KT2 AND RT2: ANTIMICROBIAL AND ANTICANCER PEPTIDES DERIVED FROM CROCODILE LEUKOCYTE EXTRACT."

52. Al Rashed N, Joji RM, Saeed NK, Bindayna KM. Detection of overexpression of efflux pump expression in fluoroquinolone-resistant Pseudomonas aeruginosa isolates. Int J Appl Basic Med Res. 2020; 10: 37-42.

53. Akbari, Vajihe, et al. "Ciprofloxacin nano-niosomes for targeting intracellular infections: an in vitro evaluation." Journal of nanoparticle research 15.4 (2013): 1556.

54. Machado, Noelia D., et al. "Niosomes encapsulated in biohydrogels for tunable delivery of phytoalexin resveratrol." $R S C$ advances 9.14 (2019): 7601-7609.

55. Gupta PV, Nirwane AM, Nagarsenker MS. Inhalable levofloxacin liposomes complemented with lysozyme for treatment of pulmonary infection in rats: effective antimicrobial and antibiofilm strategy. AAPS Pharm Sci Tech. 2018; 19:14541467.

56. Manandhar S, Singh A, Varma A, Pandey S, Shrivastava N. Evaluation of methods to detect in vitro biofilm formation by staphylococcal clinical isolates. BMC Res Notes. 2018; 11(1):714. Doi:10.1186/s13104-018-3820-9

57. Ikonomidis A, Vasdeki A, Kristo I, Maniatis AN, Tsakris A, Malizos KN, Pournaras S. Association of biofilm formation and methicillinresistance with accessory gene regulator (agr) loci in Greek Staphylococcus aureus clones. Microb Pathog. 2009 Dec; 47(6):341-4. DOI: 10.1016/j.micpath.2009.09.011. 
58. Manandhar S, Singh A, Varma A, Pandey S, Shrivastava N. Biofilm producing clinical Staphylococcus aureus isolates augmented prevalence of antibiotic resistant cases in tertiary care hospitals of Nepal. Front Microbiol. 2018; 9:2749. doi:10.3389/fmicb.2018.02749

59. Banerjee, Debjani, et al. "A review on basic biology of bacterial biofilm infections and their treatments by nanotechnology-based approaches." Proceedings of the National Academy of Sciences, India Section B: Biological Sciences (2019): 1-17.

60. Abebe, Gedif Meseret. "The Role of Bacterial Biofilm in Antibiotic Resistance and Food Contamination." International Journal of Microbiology 2020 (2020).

61. Heba S. Barakat, Mervat A. Kassem. Vancomycin-Eluting Niosomes: A New Approach to the Inhibition of Staphylococcal Biofilm on Abiotic Surfaces. AAPS PharmSciTech, Vol. 15, No. 5, October 2014 (\# 2014). DOI: 10.1208/s12249-014-0141-8.

62. Cucarella C, Tormo MA, Knecht E, Amorena B, Lasa I, Foster TJ, Penadés JR. Expression of the biofilm-associated protein interferes with host protein receptors of Staphylococcus aureus and alters the infective process. Infect Immun. 2002 Jun; 70(6):3180-6. DOI: 10.1128/IAI.70.6.3180-3186.2002

63. Manandhar S, Singh A, Varma A, Pandey S, Shrivastava N. Evaluation of methods to detect in vitro biofilm formation by staphylococcal clinical isolates. BMC Res Notes. 2018; 11(1):714. Doi:10.1186/s13104-018-3820-9

64. Lawson M, Hoth K, DeForest C, Bowman C, Anseth K. Inhibition of staphylococcus epidermidis biofilms using polymerizable vancomycin de r i v a t i v e s . Cl i n Orthop Relat Re s .2010; 468(8):2081-91

65. Kim H-J, Michael Gias EL, Jones MN. The adsorption of cationic liposomes to Staphylococcus aureus biofilms. Colloids Surf A Physicochem Eng Aspects. 1999; 149(1-3):561-570.

66. Abdelaziz AA, Elbanna TE, Sonbol FI, Gamaleldin NM, El Maghraby GM. Optimization of niosomes for enhanced antibacterial activity and reduced bacterial resistance: in vitro and in vivo evaluation. Expert Opin Drug Deliv. 2015; 12(2):163-180.

67. Zhong, Yajie, et al. "Natural Polymer-Based Antimicrobial Hydrogels without Synthetic Antibiotics as Wound Dressings." Biomacromolecules 21.8 (2020): 2983-3006.

68. Poy D, Akbarzadeh A, Ebrahimi Shahmabadi H, et al. Preparation, characterization, and cytotoxic effects of liposomal nanoparticles containing cisplatin: an in vitro study. Chem Biol Drug Des. 2016; 88: 568-573. 


\section{Figures}

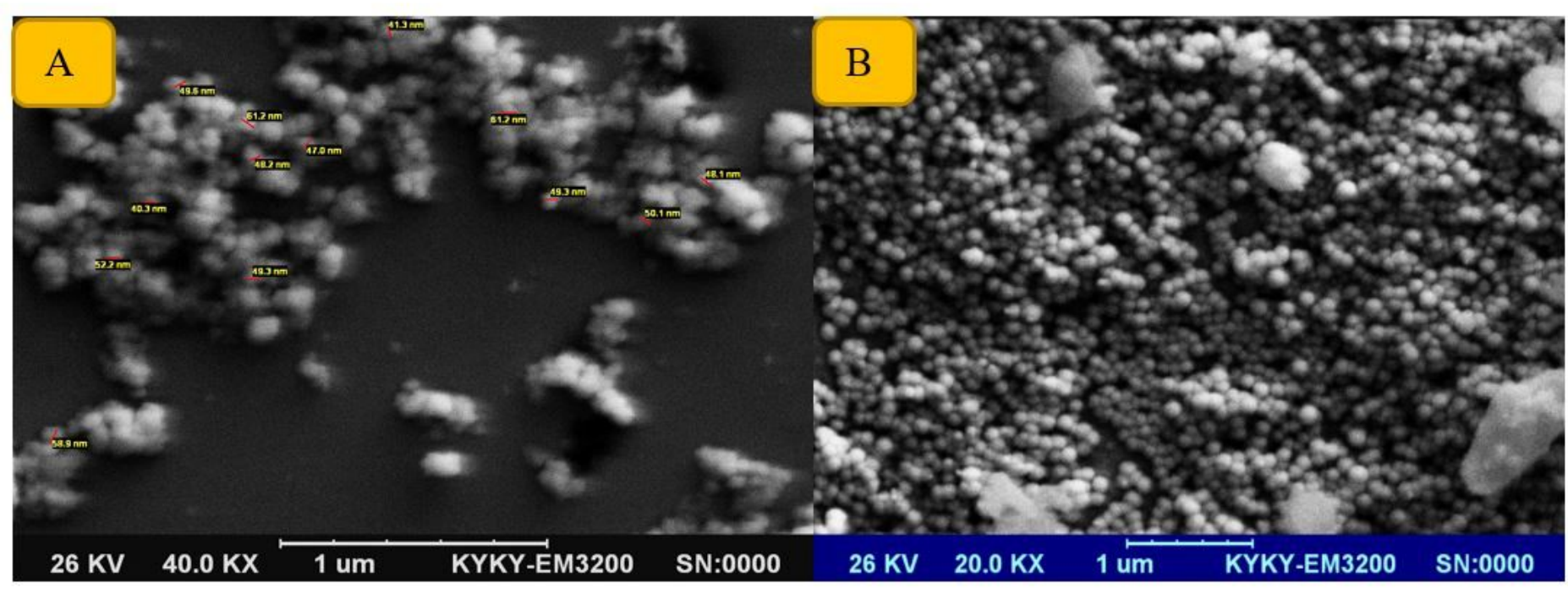

Figure 1

a: niosome-encapsulated meropenem b. the uniform spherical shape of niosome-encapsulated meropenem

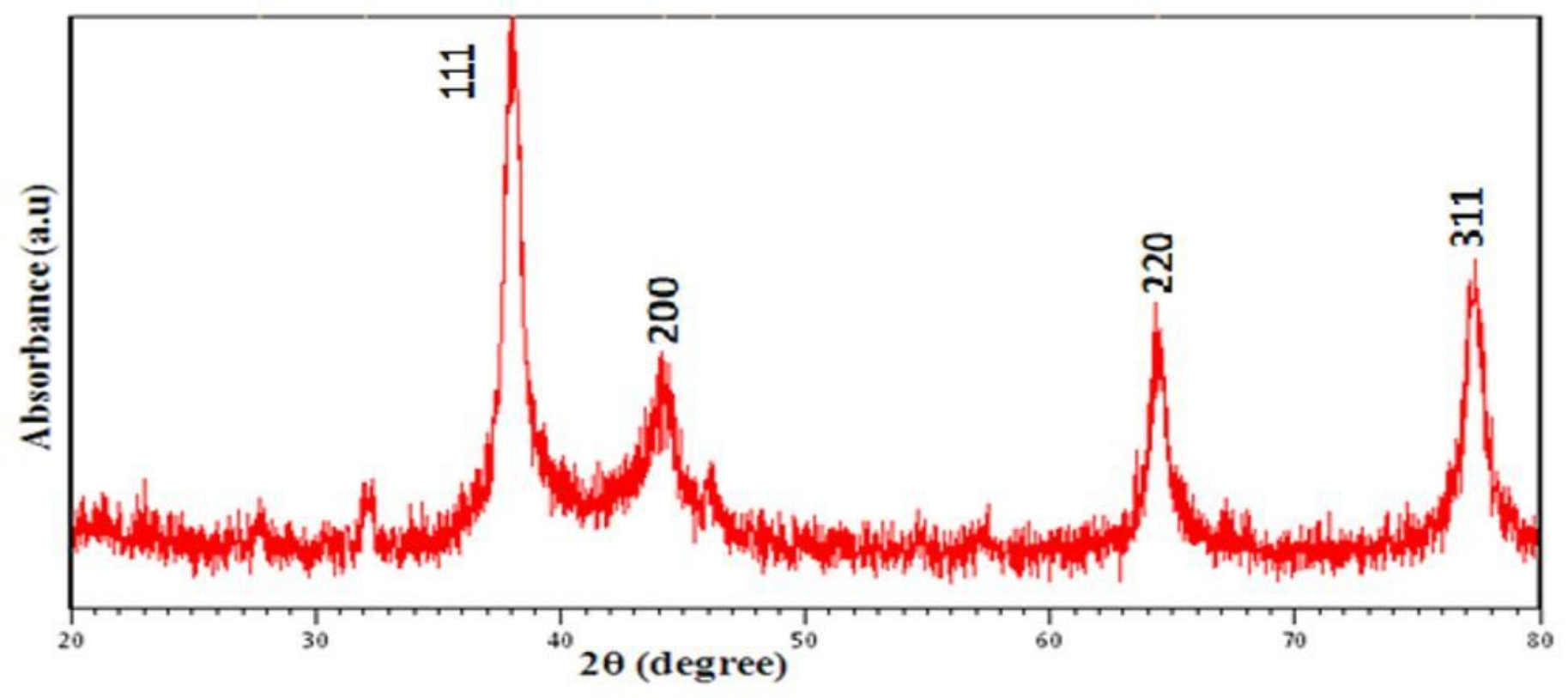

Figure 2

the XRD pattern of niosome-encapsulated meropenem 


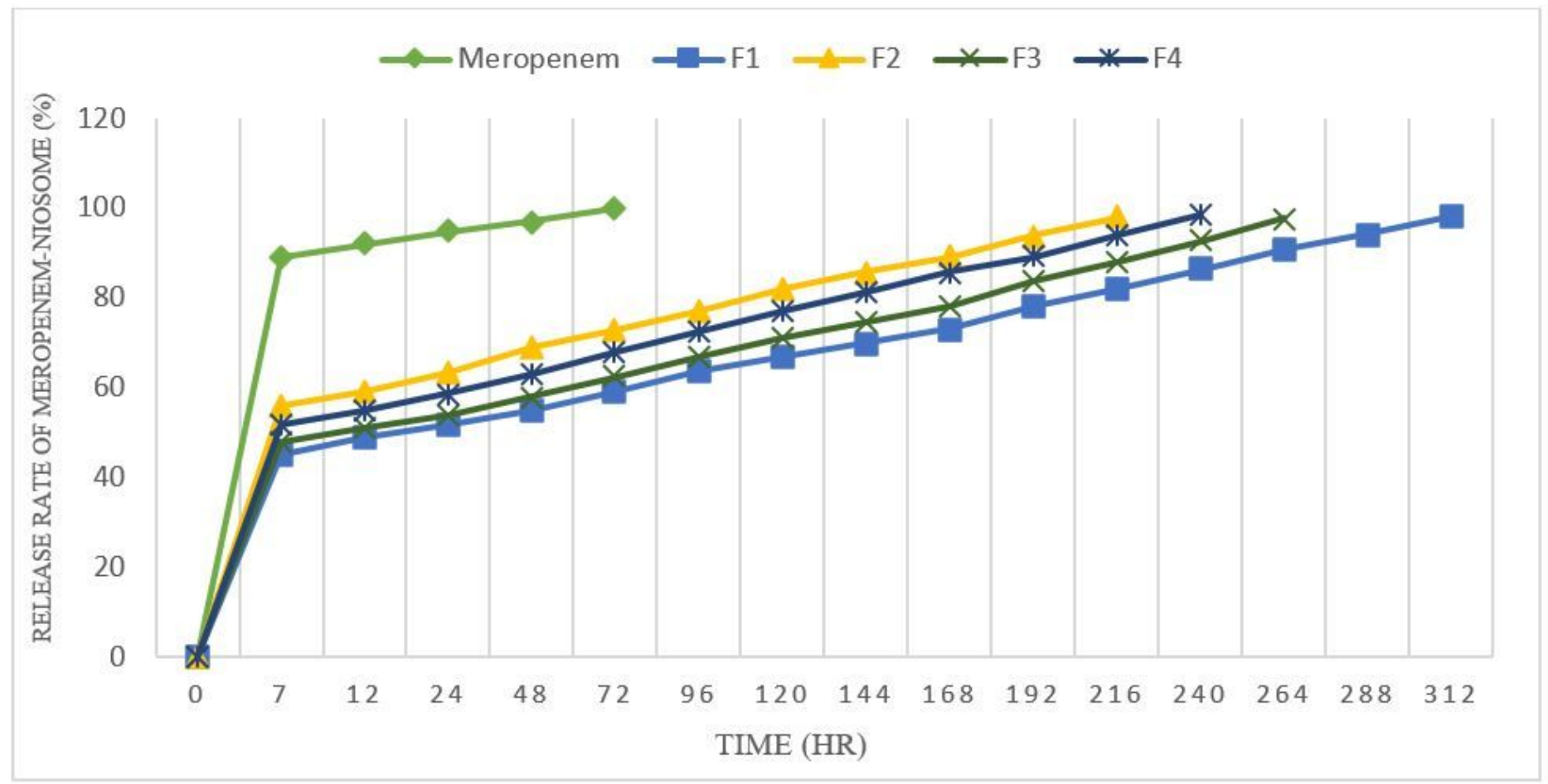

\section{Figure 3}

the rate of controlled drug release in various formulations of niosome-encapsulated meropenem compared to free meropenem. 

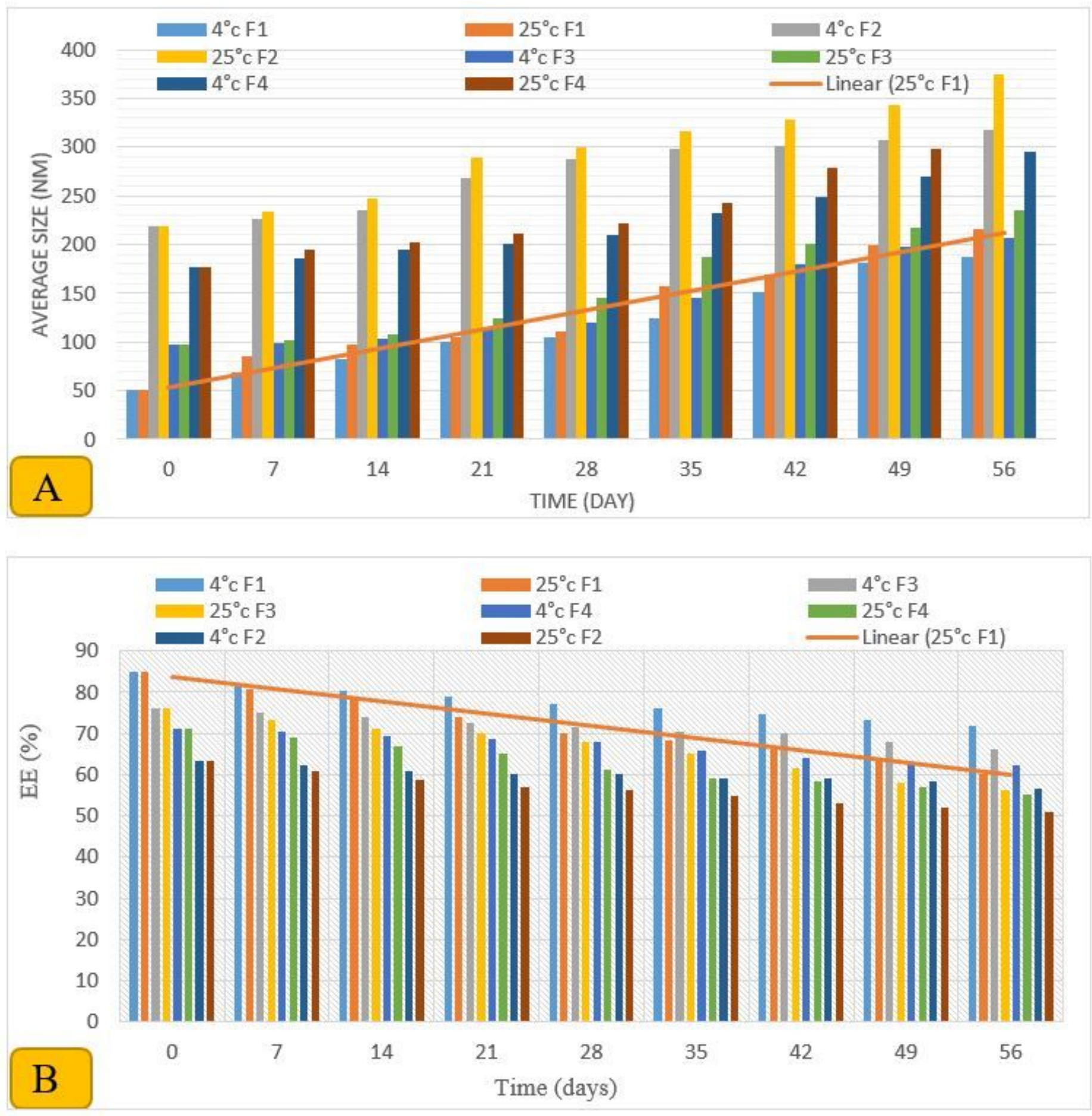

Figure 4

the impact of temperature and shelf time on average size (A) and encapsulation efficiency (B) of niosome-encapsulated meropenem 


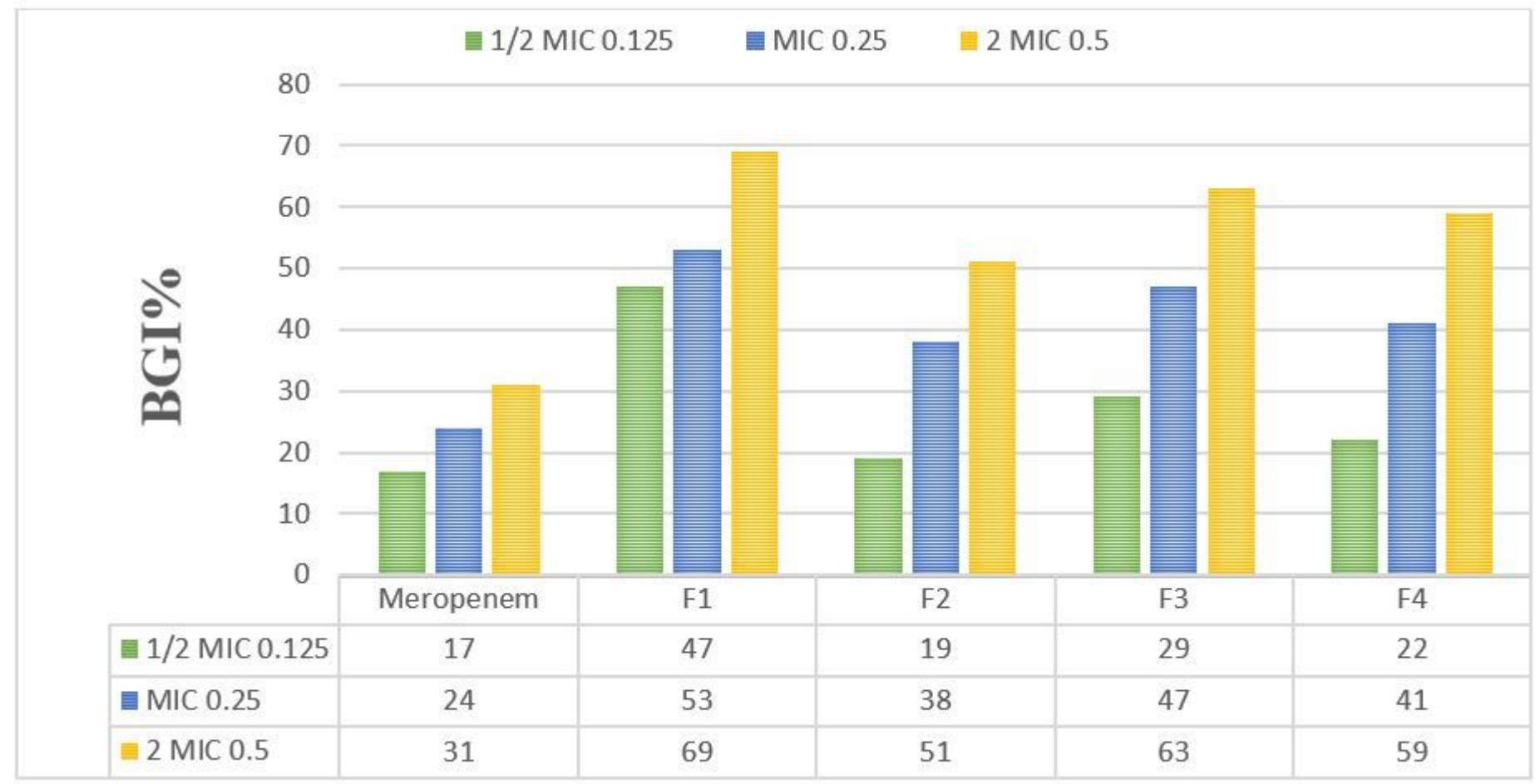

\section{Figure 5}

biofilm growth inhibition percentage of various formulations of niosome-encapsulated Meropenem 

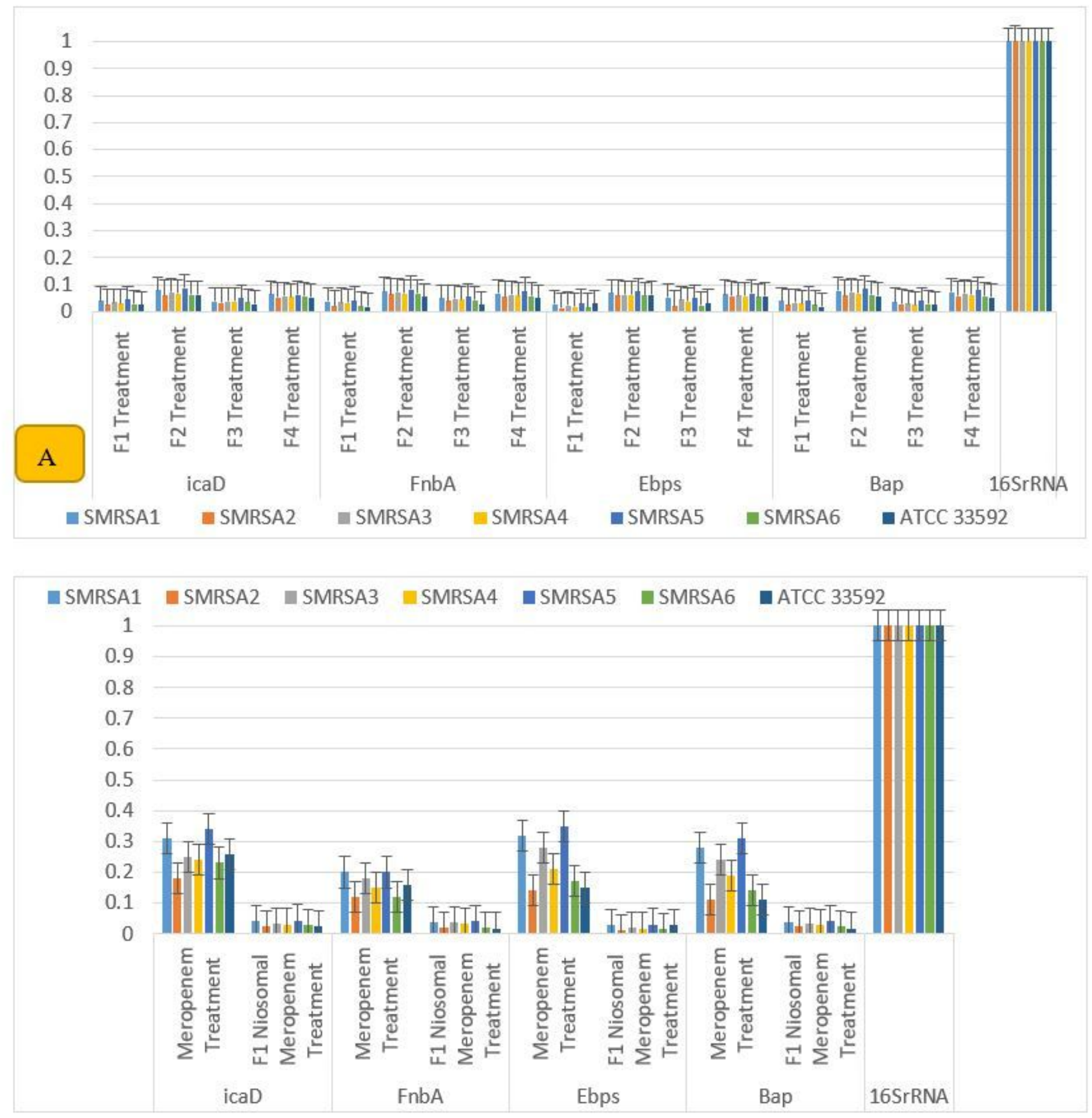

Figure 6

A. effect of various drug formulations on biofilm gene expressions B. effect of the best drug formulation (F1) on biofilm gene expression compared to free meropenem before and after treatment 


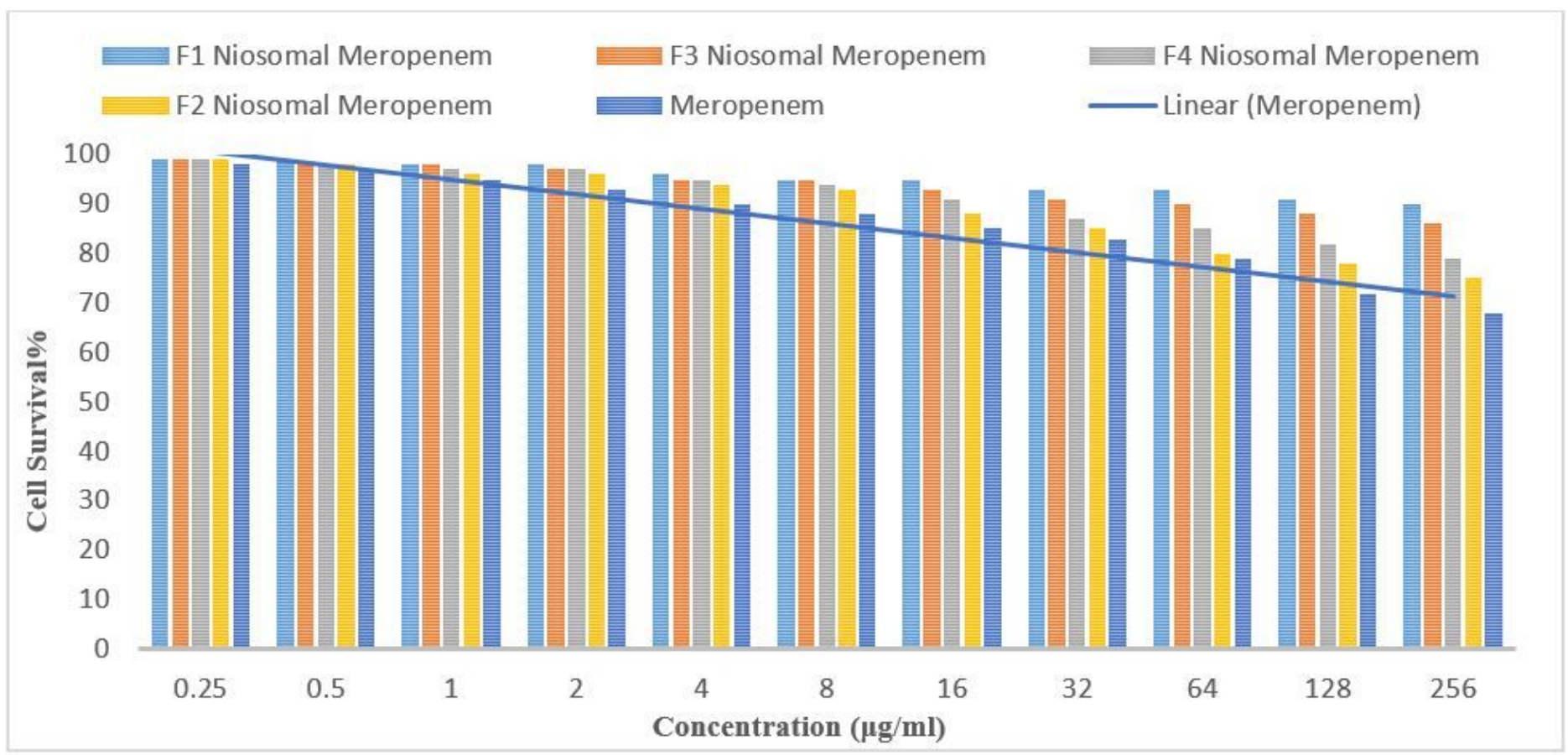

Figure 7

cell viability percentage of HDF cells treated with various formulations of niosome-encapsulated meropenem in comparison with free niosome over 24 hours

\section{Supplementary Files}

This is a list of supplementary files associated with this preprint. Click to download.

- InkedInked30534Image15227511720190306LI.jpg 